\title{
On Relationships between Nonrecurving Western North Pacific Tropical Cyclones, the Madden-Julian Oscillation, and the East Asian Subtropical Jet
}

\author{
LAWRENCE C. GLOECKLER III ${ }^{\mathrm{a}}$ AND PAUl E. ROUNDY \\ Department of Atmospheric and Environmental Sciences, University at Albany, State University of New York, Albany, New York
}

(Manuscript received 2 August 2018, in final form 30 December 2018)

\begin{abstract}
A 200-hPa zonal momentum budget is performed to examine the role that western North Pacific tropical cyclones (TCs) play in helping to organize intraseasonal extratropical circulation anomalies that occur with the Madden-Julian oscillation (MJO). Zonal wind is linearly decomposed into components that occur on MJO time scales (i.e., 20-100-day periods), as well as those that occur with lower and higher frequency. Dates during Northern Hemisphere fall that feature nonrecurving TCs within a search radius centered on a South China Sea grid point when the MJO is convectively active over the Maritime Continent and west Pacific warm pool are used to generate composites of relevant budget terms. These composites are then compared to others that are based on the full list of dates that feature a convectively active MJO in the same location during $\mathrm{NH}$ fall without regard for TC presence. Composite results highlight the primary momentum sources that guide the evolution of the $\mathrm{NH}$ extratropical zonal wind and associated mass field in each event set. TCs help to accelerate the East Asian subtropical jet that evolves with the MJO by modulating the high-frequency subtropical circulation over Southeast Asia. The phasing of this circulation with its underlying MJO time-scale component enables it to transfer momentum to the emerging subtropical jet. This momentum is integrated into the more slowly evolving flow and carried forward by other processes, which leads to the development of a westerly momentum surge along the subtropical jet that spans the length of the North Pacific Ocean.
\end{abstract}

\section{Introduction}

Many studies that are concerned with evaluating the variability of the tropical atmosphere have revealed significant associations between the Madden-Julian oscillation (MJO; e.g., Madden and Julian 1994; Zhang 2005) and an array of tropical modes that exhibit different characteristic spatial and temporal scales. Among the more widely studied of these relationships is that of the MJO and tropical cyclones (TCs). The MJO is characterized by an eastward-propagating large-scale coupling of anomalous moist deep tropical convection and circulation that evolves over periods spanning approximately 20-100 days (Roundy 2012), and it extends zonally up to $10000 \mathrm{~km}$ (Matthews et al. 2013), yielding a planetary-scale (zonal wavenumbers 1 and 2) footprint. MJO convection usually achieves its greatest amplitude over the tropical Indian and western Pacific Ocean

${ }^{\text {a }}$ Current affiliation: Riskpulse, Austin, Texas.

Corresponding author: Lawrence C. Gloeckler III, lgloeckler@ albany.edu basins, where it couples to the warmest sea surface on the planet (Zhang 2005). Outside of these basins, where sea surface temperatures are generally lower and less able to sustain organized tropical convection, its broad circulation dominates its structure, and this circulation radiates eastward across the Western Hemisphere at a higher velocity than when it is coupled to convection.

The MJO effectively modulates large-scale circulation, temperature, and moisture profiles across the domain through which it propagates, and because of its global reach, these effects are not limited to a particular part of the tropics. Its effect on its environment influences TC organization across various ocean basins. Liebmann et al. (1994) examined physical links between the MJO and Indian Ocean and western Pacific Ocean TCs. They found that TC frequency in both basins is increased during the convectively active phase of the MJO but that the ratio of mature storms to those less organized remains unchanged relative to periods of convective suppression. They related enhanced TC activity to the development of low-level cyclonic relative vorticity and convergence anomalies westward and poleward of enhanced MJO convection. Short periods of highly 
anomalous low-level westerly wind, termed westerly wind bursts, can accompany the MJO as it amplifies over the west Pacific warm pool, and these anomalous westerly wind events have been linked to TC genesis (often manifesting as twin cyclones about the equator) in this region (Keen 1982; $\mathrm{Yu}$ and Rienecker 1998; Zhu et al. 2003; Seiki and Takayabu 2007). Sobel and Maloney (2000) evaluated relationships between the MJO and western North Pacific TCs through a barotropic wave activity flux framework. Their results demonstrated enhanced wave activity convergence (wave accumulation) in association with active west Pacific MJO phases. As precursor disturbances cross the western North Pacific basin during a favorable MJO phase, low-level flow convergence accompanying enhanced convection in this region can help to amplify these disturbances and increase their likelihood of undergoing cyclogenesis.

Relationships between the MJO and TC frequency have also been documented in other ocean basins. Maloney and Hartmann (2000) presented evidence linking low-level westerly wind anomalies and associated anomalous lowlevel cyclonic relative vorticity accompanying the westerly phase of the MJO to a fourfold increase in eastern North Pacific TC occurrence relative to periods that are dominated by its easterly phase. Aiyyer and Molinari (2008) demonstrated an association between the MJO and preferred barotropic eddy growth states over the Gulf of Mexico and eastern North Pacific Ocean, wherein the MJO influences the spatial distribution of eddy growth activity, and TCs tend to organize where this growth is maximized. They showed that during convectively inactive MJO phases, eddy growth tends to be most concentrated across the eastern North Pacific Ocean, but it expands to the Gulf of Mexico when MJO convective activity increases. Barrett and Leslie (2009) found a statistically significant link between North Atlantic TC occurrence and frequency of landfall and the phase of the MJO. They reasoned that the MJO increases the likelihood of TC formation and intensification across this ocean basin by enhancing large-scale upper-tropospheric divergence as its circulation transits the Western Hemisphere. Klotzbach (2010) noted important relationships between the MJO, vertical wind shear, and relative humidity across the North Atlantic basin and applied these relationships to investigate $\mathrm{MJO}$ influence on North Atlantic TC activity. He reported that during phases 1 and 2 of the real-time multivariate MJO (RMM) index (Wheeler and Hendon 2004), vertical wind shear values across the North Atlantic basin [including across the main development region (MDR), where the bulk of North Atlantic TCs form] are as much as $4 \mathrm{~m} \mathrm{~s}^{-1}$ weaker than during RMM phases 6 and 7. This favorable large-scale environmental modification accompanying the westerly phase of the MJO was associated with a threefold increase in major North Atlantic hurricanes and major hurricane days across the MDR relative to peak easterly MJO phases (RMM phases 6 and 7) during the period of study. Camargo et al. (2009) developed a global TC genesis potential index to quantify the extent to which different environmental variables modulated by the MJO contribute to the likelihood of TC formation. They reported that the MJO primarily contributes to TC genesis through its effect on midlevel relative humidity and secondarily through its effect on low-level absolute vorticity.

The aforementioned studies highlight significant physical and/or statistical relationships between the MJO and TCs across different regions of the global tropics. Yet little work has been done to assess these relationships in the context of the global circulation. Both modes of tropical variability effectively modulate the largescale extratropical circulation. For example, the MJO has been linked to the establishment of anomalous temperature and precipitation patterns that occur across different regions of the extratropical Northern and Southern Hemispheres (e.g., Higgins et al. 2000; Jones et al. 2004; Donald et al. 2006; L'Heureux and Higgins 2008; Riddle et al. 2013; Zhou et al. 2012; Matsueda and Takaya 2015; Schreck et al. 2015; Alvarez et al. 2016) via Rossby wave train excitation poleward of its convective envelope (e.g., Lukens et al. 2017). TCs have been connected to similar sets of anomalous circulation outcomes through their roles in initiating periods of highly amplified extratropical flow (e.g., Cordeira and Bosart 2010; Archambault et al. 2013; Parker et al. 2013; Grams and Blumer 2015; Barton et al.2016). The prevalence of TCs in association with the MJO suggests that they can affect the extratropical response to MJO convective forcing for varying periods of time, whether by moving out of the tropics and interacting directly with higher-latitude waveguides, modulating the spatial distribution of anomalous convection associated with the MJO, a combination thereof, or through additional pathways. Gloeckler and Roundy (2019) performed a statistical analysis featuring correlations of anomalous 200-hPa geopotential height to evaluate associations between western North Pacific TCs and MJO-related large-scale pattern organization across a domain centered on North America. Their goal was to identify instances in which these TCs are associated with extratropical circulation outcomes that align with or diverge from those that are expected to occur in conjunction with a particular MJO convective forcing state and to assess whether those outcomes are distinguishable from random chance. They found that, for certain combinations of MJO and TC activity, TC presence is associated with a subsequent circulation response that is unlikely 
to be randomly reproduced. However, their assessments were primarily statistical in nature, leaving room for physical attribution studies.

Since the MJO and TCs generally occur on different time scales, quantifying their mutual contributions to the development of large-scale intraseasonal circulation anomalies can be challenging. This study employs a zonal momentum budget following the methods of Sakaeda and Roundy (2015) to examine TC influence on the evolution of the intraseasonal extratropical circulation during the Northern Hemisphere $(\mathrm{NH})$ fall season. Relevant budget terms are averaged over a set of dates in which the MJO is convectively active over the Maritime Continent and adjacent west Pacific Ocean when nonrecurving TCs are present within a circular search area centered on a South China Sea grid point. Resulting zonal wind accelerations are compared to those that are based on the full population of convectively active MJO dates from which the TC-based date set is derived in order to highlight differences that relate to TC presence. The set of combined MJO-TC events featured in this study - the same set highlighted in Gloeckler and Roundy (2019)—was selected to emphasize associations between nonrecurving TCs, which are significantly underrepresented in the literature, a mature Maritime Continent-west Pacific MJO event, and subtropical jet amplification over East Asia and the adjacent western North Pacific (e.g., Moore et al. 2010). Gloeckler and Roundy (2019) found that this particular set of combined MJO-TC events is associated with an upper-level circulation response across a domain centered on North America that opposes the pattern that lags all convectively active NH fall Maritime Continentwest Pacific MJO events without regard for TC presence. It is hypothesized that the TCs included in this set of events contribute to this opposite downstream circulation outcome by modulating the East Asian subtropical jet. Section 2 provides an overview of data and describes the momentum budget methodology, and section 3 presents salient results. Finally, section 4 offers conclusions and offers suggestions for future work.

\section{Data and methods}

\section{a. Data and event identification}

The bulk of the large-scale circulation analysis for this study was accomplished using $200-\mathrm{hPa}$ geopotential height and zonal and meridional wind data from the Climate Forecast System Reanalysis (CFSR; Saha et al. 2010a,b) dataset for the period 1979-2010 and an archive of the operational Climate Forecast System, version 2 (CFSv2; Saha et al. 2011, 2014), for the period
2011-12. CFSR and CFSv2 data were obtained from the National Center for Atmospheric Research (NCAR) Computational and Information Systems Laboratory (CISL) Research Data Archive (RDA). The data were provided on a $2.5^{\circ}$ horizontal grid spanning the full globe and at 6-hourly time intervals corresponding to 0000 , 0600, 1200, and 1800 UTC. Daily averages of each variable were computed, and anomalies were generated by removing the long-term (1981-2010) mean and the first three harmonics of the seasonal cycle at each grid point.

MJO events were identified using the event classification scheme described by Gloeckler and Roundy (2019). Briefly, dates during NH fall (SeptemberNovember) and the period of study (1979-2012) in which the amplitude of the RMM index (Wheeler and Hendon 2004) exceeded 0.5 standard deviations were identified. One standard deviation is commonly set as a threshold to distinguish between periods of time in which the MJO is active (greater than this threshold) and inactive (less than or equal to this threshold), but this selection is arbitrary. Gloeckler and Roundy (2019) noted that their results based on this lower threshold were not statistically significantly different from those obtained by raising the threshold to the conventional value of one standard deviation and thus advocated for the use of a lower threshold to increase sample size. After a list of dates was compiled, MJO events for each phase of the RMM index were constructed by finding sets of dates that occurred within 8 days of one another during the same RMM phase.

TC events were identified using the International Best Track Archive for Climate Stewardship (IBTrACS), version 3 (revision 6), dataset (Knapp et al. 2010a,b). IBTrACS provides storm position, intensity, classification, basin, name, and several other relevant parameters pertaining to TCs that occurred worldwide beginning in 1848. Storms that achieved tropical status during the season and period of study were stratified by the curve clustering algorithm employed by Gloeckler and Roundy (2019) and retained for further examination. The clustering algorithm, first introduced by Gaffney (2004), leverages polynomial regression to objectively group TC tracks with similar origin points and trajectories. Two clusters yielded a recurving and a nonrecurving storm set (see Fig. 5 in Gloeckler and Roundy 2019). Finally, the refined list of TCs was binned into geographical groups by constructing a $7.5^{\circ}$ search radius around each grid point across the global domain. This radius was selected because it generally yields a large enough sample of events while maintaining geographical consistency among TCs. TC groups aid in the identification of storms that occur proximate to one another during a specified RMM phase. 


\section{b. Zonal momentum budget procedure}

The zonal momentum budget employed in this study follows the procedure outlined by Sakaeda and Roundy (2015). Budget analysis begins with an equation to calculate the local zonal wind tendency on isobaric surfaces:

$$
\frac{\partial u}{\partial t}=-\mathbf{v} \cdot \nabla u-\frac{\partial \Phi}{\partial x}+f v+\frac{u v \tan \phi}{a}+X,
$$

where $\mathbf{v}=\langle u, v, \omega\rangle, \Phi$ represents geopotential at constant pressure, $f$ is the Coriolis parameter, $\phi$ represents latitude, $a$ represents the radius of Earth, and $X$ includes the sum of all terms whose contributions to the intraseasonal (20-100 day) zonal wind tendency are considered negligible (i.e., Coriolis torque on the vertical wind, the vertical curvature term, friction, vertical diffusion zonal acceleration, and convective zonal momentum mixing acceleration), along with a residual. The second-to-last term on the right-hand side (rhs) of (1) is brought about by Earth's curvature. Sakaeda and Roundy (2015) included this curvature term in $X$ because it represents a quantity that is vanishingly small near the equator where their study was focused, but it becomes nonnegligible at higher latitudes when assessed on intraseasonal time scales.

Each term on the rhs of (1) is linearly decomposed into three temporal bands by first applying a Fourier transform, then zeroing out the resultant coefficients that are not included in the specified band, and finally applying an inverse transform to these coefficients. TC-related signals are not removed from any field before filtering. Bands encompass background (periods exceeding 100 days; denoted by an overbar), intraseasonal (denoted by an asterisk), and transient (periods less than 20 days; denoted by a prime symbol) time scales, and they yield the original total field when summed:

$$
u=\bar{u}+u^{*}+u^{\prime} .
$$

Consistent with Sakaeda and Roundy (2015), the background state includes the long-term average, low-frequency variability like El Niño-Southern Oscillation, as well as the seasonal cycle.

Following linear decomposition, an intraseasonal bandpass filter is applied to the terms $-\mathbf{v}^{*} \cdot \nabla u^{*}$ and $-\mathbf{v}^{\prime} \cdot \nabla u^{\prime}$, which project onto the intraseasonal band in addition to shorter and longer time scales. The need to postfilter these terms relates to their inclusion of nonconstant variable products (e.g., the product of $u^{\prime}$ and $\partial u^{\prime} / \partial x$ ), which can yield output that projects onto higher and lower frequencies because of the inherent nonlinearity of these operations, along with the intention to assess contributions of these features to the intraseasonal band. Terms like $-\mathbf{v}^{*} \cdot \nabla u^{\prime}$ do not contribute to intraseasonal zonal wind tendency because intraseasonal variables like $\mathbf{v}^{*}$, which are roughly constant on transient time scales, act to amplify transient variables like $u^{\prime}$ without changing their frequency.

Filtered terms whose values are at least one order of magnitude less than the zonal wind tendency $\left(10^{-5} \mathrm{~m} \mathrm{~s}^{-2}\right)$, or those that do not contribute to the intraseasonal band, are removed from the analysis. The remaining terms yield the intraseasonal zonal wind tendency equation used in this study:

$$
\begin{aligned}
& \frac{\partial u^{*}}{\partial t} \approx \underbrace{-\bar{u} \frac{\partial u^{*}}{\partial x}}_{1 \mathrm{a}} \underbrace{-u^{*} \frac{\partial \bar{u}}{\partial x}}_{1 \mathrm{~b}}-\underbrace{\left[u^{*} \frac{\partial u^{*}}{\partial x}\right]^{*}}_{1 \mathrm{c}}-\underbrace{\left[u^{\prime} \frac{\partial u^{\prime}}{\partial x}\right]^{*}}_{1 \mathrm{~d}} \\
& \underbrace{-\bar{v} \frac{\partial u^{*}}{\partial y}}_{2 \mathrm{a}}-\underbrace{v^{*} \frac{\partial \bar{u}}{\partial y}}_{2 \mathrm{~b}}-\underbrace{\left[v^{*} \frac{\partial u^{*}}{\partial y}\right]^{*}}_{2 \mathrm{c}}-\underbrace{\left[v^{\prime} \frac{\partial u^{\prime}}{\partial y}\right]^{*}}_{2 \mathrm{~d}} \\
& \underbrace{-\bar{\omega} \frac{\partial u^{*}}{\partial p}}_{3 \mathrm{a}} \underbrace{-\omega^{*} \frac{\partial \bar{u}}{\partial p}}_{3 \mathrm{~b}}-\underbrace{\left[\omega^{*} \frac{\partial u^{*}}{\partial p}\right]^{*}}_{3 \mathrm{c}}-\underbrace{\left[\omega^{\prime} \frac{\partial u^{\prime}}{\partial p}\right]^{*}}_{3 \mathrm{~d}} \\
& \underbrace{-\frac{\partial \Phi^{*}}{\partial x}+f v^{*}}_{4}+\underbrace{\left[\frac{u v \tan \phi}{a}\right]^{*}}_{5} .
\end{aligned}
$$

Each term is labeled for reference in the text. All space and time derivatives are approximated using the five-point stencil formula:

$$
f^{\prime}(x) \approx \frac{-f(x+2 h)+8 f(x+h)-8 f(x-h)+f(x-2 h)}{12 h},
$$

where $x$ represents a point in space (for space derivatives) or time (for time derivatives) and $h$ denotes gridpoint or temporal spacing in meters or seconds, respectively.

\section{c. Assessment of statistical significance}

Bootstrap resampling was applied to test sample statistics of gridded data for local significance. The list of dates over which a given statistic was calculated was resampled 1000 times, and probability distributions were generated at each grid point from these resampled dates. The inner $95 \%$ of these distributions was selected to establish local significance, meaning that if the value of the statistic at a selected grid point fell outside of this range, it was considered to be statistically significantly different from zero at the $95 \%$ level 

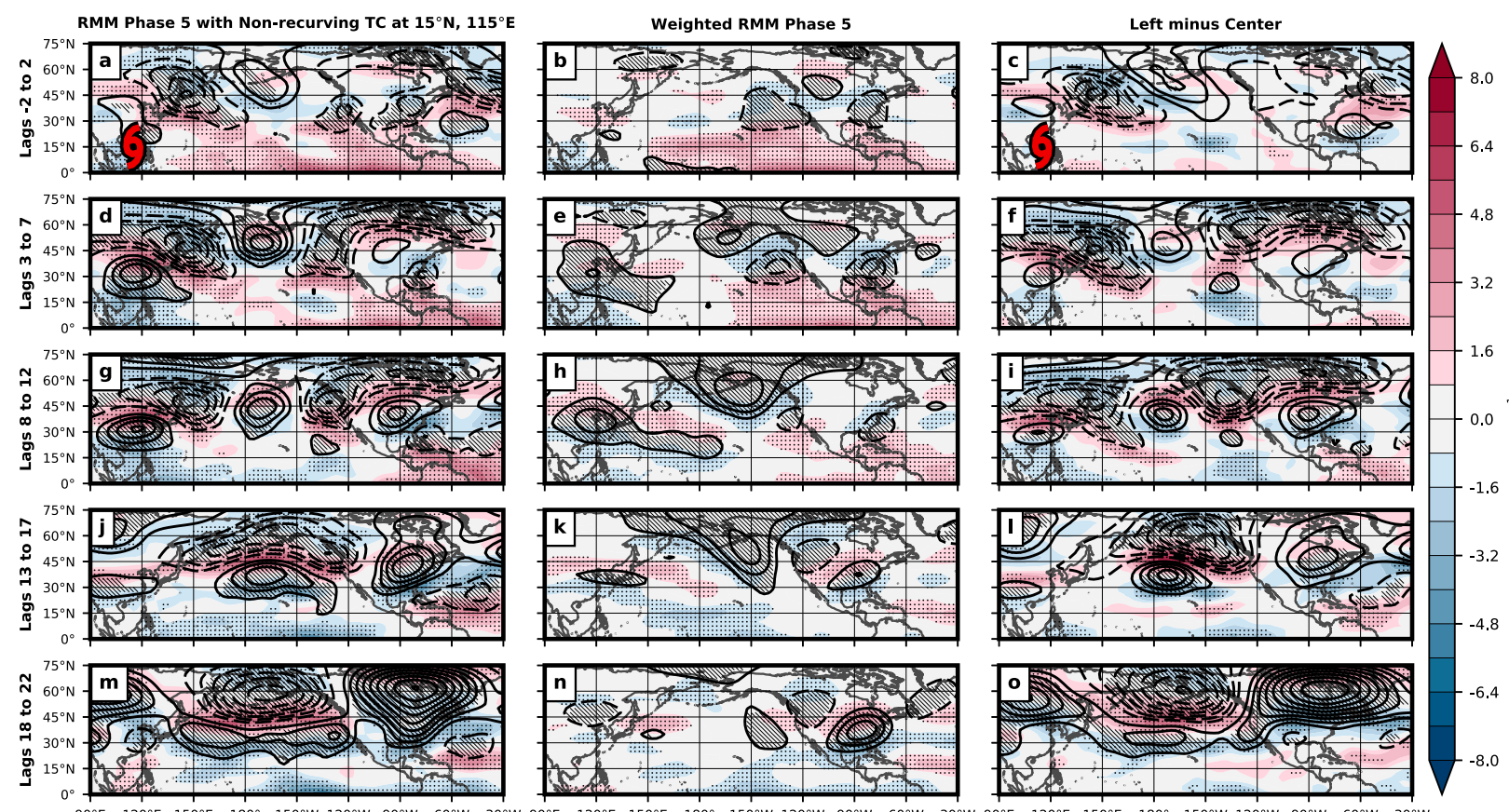

FIG. 1. Intraseasonal filtered 200-hPa geopotential height anomalies (black contours; gpm; solid contours indicate positive values; contour interval is $10 \mathrm{gpm}$, beginning at $\pm 10 \mathrm{gpm}$ ) and intraseasonal filtered 200-hPa zonal wind anomalies (shaded; $\mathrm{m} \mathrm{s}^{-1}$ ), averaged over sequential 5-day periods (pentads) between 2 days before and 22 days after the composite reference dates (lag zero). Each pentad is represented by a row, and all days included in each pentad are labeled along the $y$ axis of their corresponding left-column panel.(a),(d),(g),(j),(m) The TC-based RMM phase-5 composite (69 days included), (b),(e),(h),(k),(n) the full population RMM phase-5 composite (468 days included), and (c),(f),(i),(l),(o) the result of subtracting the center column from the left column. Statistically significant geopotential height anomalies are hatched, and statistically significant zonal wind anomalies are stippled. Red TC symbols in (a) and (c) mark the grid point at the center of the search radius used to identify TCs at lag zero.

at that grid point. A modification was applied to this test to mitigate the risk of falsely claiming local significance [known as the false discovery rate (FDR)]. This modification incorporates $p$ values that are generated for each grid point after local bootstrap probability distributions are constructed. A threshold global $p$ value is determined from the sorted list of local $p$ values, and this value becomes the new local significance level for all grid points. A more thorough explanation of this modification is found in Wilks $(2006,2016)$, and its application as it relates to gridded data in the context of this study is described in section $2 \mathrm{~d}$ of Gloeckler and Roundy (2019). Bootstrap resampling was also applied more broadly to test non-grid-based results for significance at the $95 \%$ level. These tests did not employ the FDR modification.

\section{Results}

\section{a. Large-scale pattern overview}

Pentad-mean 200-hPa geopotential height and zonal wind anomalies associated with a subset of RMM phase- 5 dates (69 days) that feature TCs within a $7.5^{\circ}$ search radius centered on $15^{\circ} \mathrm{N}, 115^{\circ} \mathrm{E}$ ( $\mathrm{TC}$ based), and the full set of RMM phase-5 dates (468 days) without regard for TC presence (full population), are displayed for comparison in Fig. 1. The left column corresponds to the TC-based composite, the center column corresponds to the full population composite, and the right column shows the result of subtracting the center column from the left column. As in Gloeckler and Roundy (2019), MJO events contained in the full population composite (Figs. 1b,e,h,k) were weighted according to the number of days in which TCs contained in the TC-based composite (Figs. 1a,d,g,j) were present in each month of NH fall during the period 1979-2012. This weighting ensures more accurate event set comparisons because TCs of a certain type might occur preferentially during a particular time of the season, and the extratropical response to tropical convective forcing undergoes an adjustment as the background circulation state evolves with the seasonal cycle. Each composite features an anomalous upper-level Rossby wave train (alternating regions of solid and dashed contours) that disperses across the North Pacific and North America, but these wave trains and their associated zonal wind 


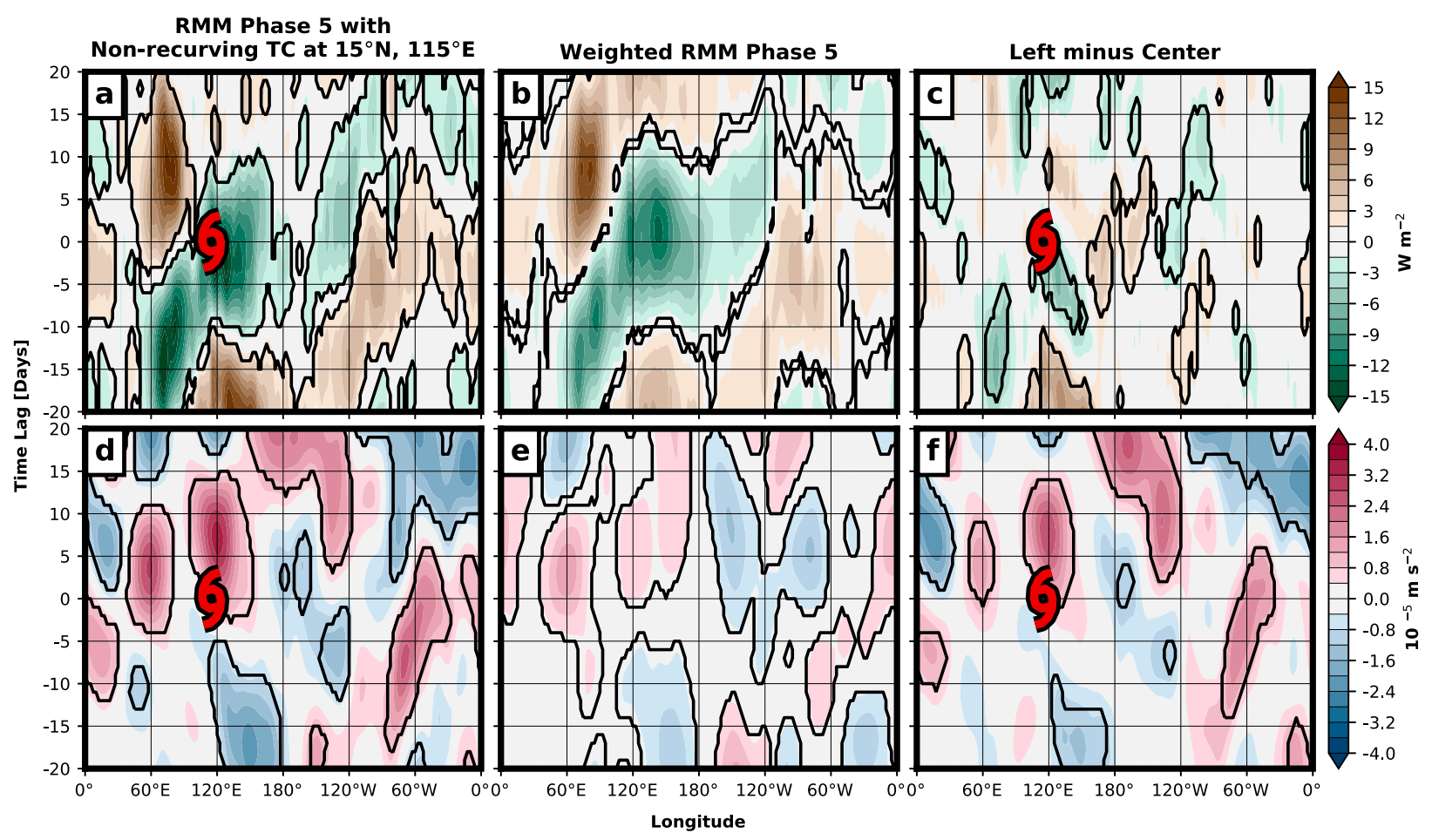

FIG. 2. Longitude-time diagrams of (a)-(c) intraseasonal filtered OLR anomalies averaged between the equator and $15^{\circ} \mathrm{N}$ and (d)-(f) intraseasonal filtered $200-\mathrm{hPa}$ zonal wind anomalies averaged between $30^{\circ}$ and $50^{\circ} \mathrm{N}$. Columns are ordered as in Fig. 1 . Statistically significant anomalies are outlined in solid black contours. Red TC symbols in (a), (c), (d), and (f) mark the center of the TC search radius in time and longitude.

anomalies quickly develop different structures. Differences first arise across East Asia and the adjacent northwest Pacific Ocean in association with the development of an anomalous subtropical jet streak that achieves greater amplitude in the TC-based composite (Fig. 1c), and they expand eastward in subsequent pentads in conjunction with subtropical jet extension (e.g., Fig. 1o).

The greatest differences in upper-level circulation between the two composite sets shown in Fig. 1 originate poleward and eastward of the TC search radius marked at its center by the red TC symbol (Fig. 1c). This observation suggests a physical link between the composite TC and the poleward large-scale circulation response that is masked by other circulation states included in the full population composite average. Figure 2 presents longitude-time diagrams of intraseasonal filtered OLR anomalies averaged between the equator and $15^{\circ} \mathrm{N}$ (Figs. 2a-c), and intraseasonal filtered 200-hPa zonal wind anomalies averaged between $30^{\circ}$ and $50^{\circ} \mathrm{N}$, for each composite and the difference between them. An eastward-propagating zonally broad envelope of enhanced convection (suggested by negative OLR anomalies depicted in green shading) flanked by regions of suppressed convection (suggested by brown shading) is present in both composites (Figs. 2a,b). These convective signals evolve on MJO time scales, and they possess similar structure and amplitude, but Fig. 2c highlights subtle differences between them. One of these key differences manifests as a statistically significant zonally narrow westward-propagating envelope of enhanced convection that bisects the broader MJO convective envelope and traverses the TC search radius. This convective signal is not likely to solely reflect the composite TC because tests suggest that it is present substantially longer than the large majority of TCs in the sample. Wavenumber-frequency spectrum analysis reveals that it projects most onto the equatorial Rossby (ER) wave band (periods of 10-100 days and wavenumbers 1-15 westward; not shown). The superposition of ER waves and the MJO can yield a favorable large-scale environment for TC organization (e.g., Frank and Roundy 2006), so it is no surprise that Fig. 2c suggests a link between these three modes of tropical variability.

A statistically significant upper-level intraseasonal westerly wind anomaly centered on $120^{\circ} \mathrm{E}$ emerges in both composites prior to lag zero and peaks in amplitude several days later. Its development is consistent with the upper-level circulation response to MJO convective forcing (e.g., Kiladis et al. 2005; Moore et al. 2010), 

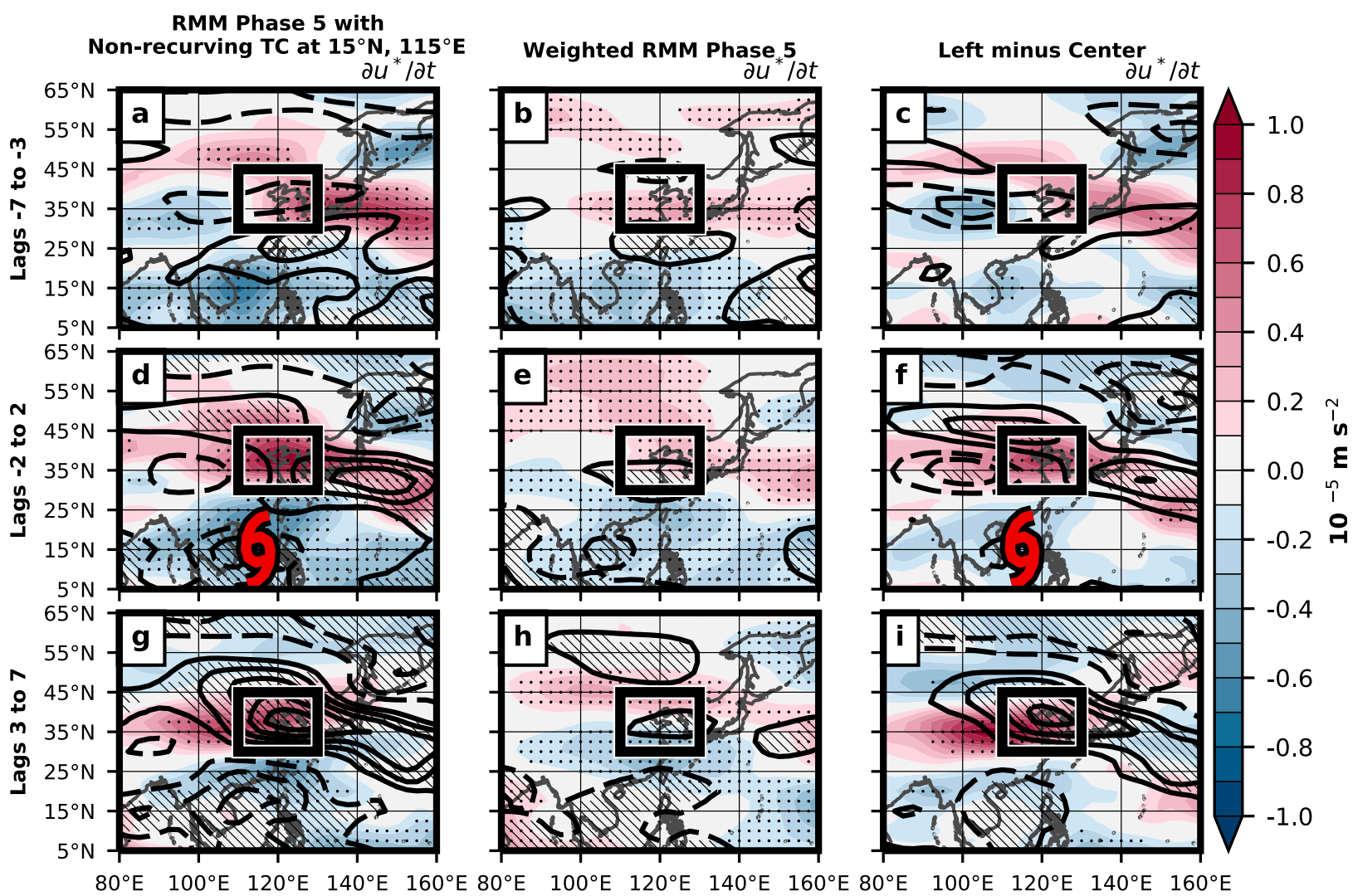

FIG. 3. The 200-hPa intraseasonal zonal wind tendency (color shading; $1 \times 10^{5} \mathrm{~m} \mathrm{~s}^{-2}$ ) and intraseasonal filtered 200-hPa zonal wind anomalies (black contours; $\mathrm{m} \mathrm{s}^{-1}$; solid contours indicate positive values; contour interval is $1 \mathrm{~m} \mathrm{~s}^{-1}$, beginning at $\pm 1 \mathrm{~m} \mathrm{~s}{ }^{-1}$ ) averaged over three sequential 5-day periods (pentads) between 7 days before and 7 days after the composite reference dates (lag zero). Each pentad is represented by a row, and all days included in each pentad are labeled along the $y$ axis of their corresponding left-column panel. Columns are ordered as in Fig. 1. Statistically significant zonal wind anomalies are hatched, and statistically significant zonal wind tendency is stippled. The black boxes in each panel outline the averaging box referenced in section 3b(1). (d),(f) Red TC symbols mark the grid point at the center of the search radius used to identify TCs at lag zero. The term in (3) indicated by shading is labeled above the top-right corner of each top-row panel.

which manifests as an anomalous subtropical upperlevel anticyclone poleward of MJO convection, and a strengthening and poleward shifting of the subtropical jet relative to its climatological state. Its presence in both composites suggests that it is linked to the MJO, yet it is more than 3 times stronger in the TC-based composite than in the full population composite. It also appears to possess a westward-evolving component in the TC-based composite (its western edge expands westward with increasing time lag), while it exhibits a gradual eastward evolution in the full population composite, which is more consistent with a canonical subtropical jet response to MJO convection (e.g., Moore et al. 2010). The strength and spatial evolution of the TC-based composite anomaly suggests a link to the westward-moving convective signal (and the composite TC) embedded within the broader MJO convective envelope (Fig. 2c). Figure $2 \mathrm{f}$ reveals that the aforementioned intraseasonal zonal wind differences are statistically significant and that other statistically significant differences arise downstream at subsequent lags.

\section{b. The East Asian intraseasonal subtropical jet response}

\section{1) PRIMARY MOMENTUM SOURCES}

The intraseasonal zonal wind anomaly positioned poleward of MJO convection in Figs. 1a, 1b, 2a, and 2b is intriguing because it possesses a clear physical relationship to the convection, yet its structure and amplitude differ greatly between the two composites. A box bounded to the west and east by $110^{\circ}$ and $130^{\circ} \mathrm{E}$ and to the south and north by $30^{\circ}$ and $45^{\circ} \mathrm{N}$ was constructed to evaluate this intraseasonal zonal wind signal and its associated tendency in order to determine its predominant momentum sources in each event set. Figure 3 presents these fields across a domain surrounding this box, which is outlined for reference in each panel. 

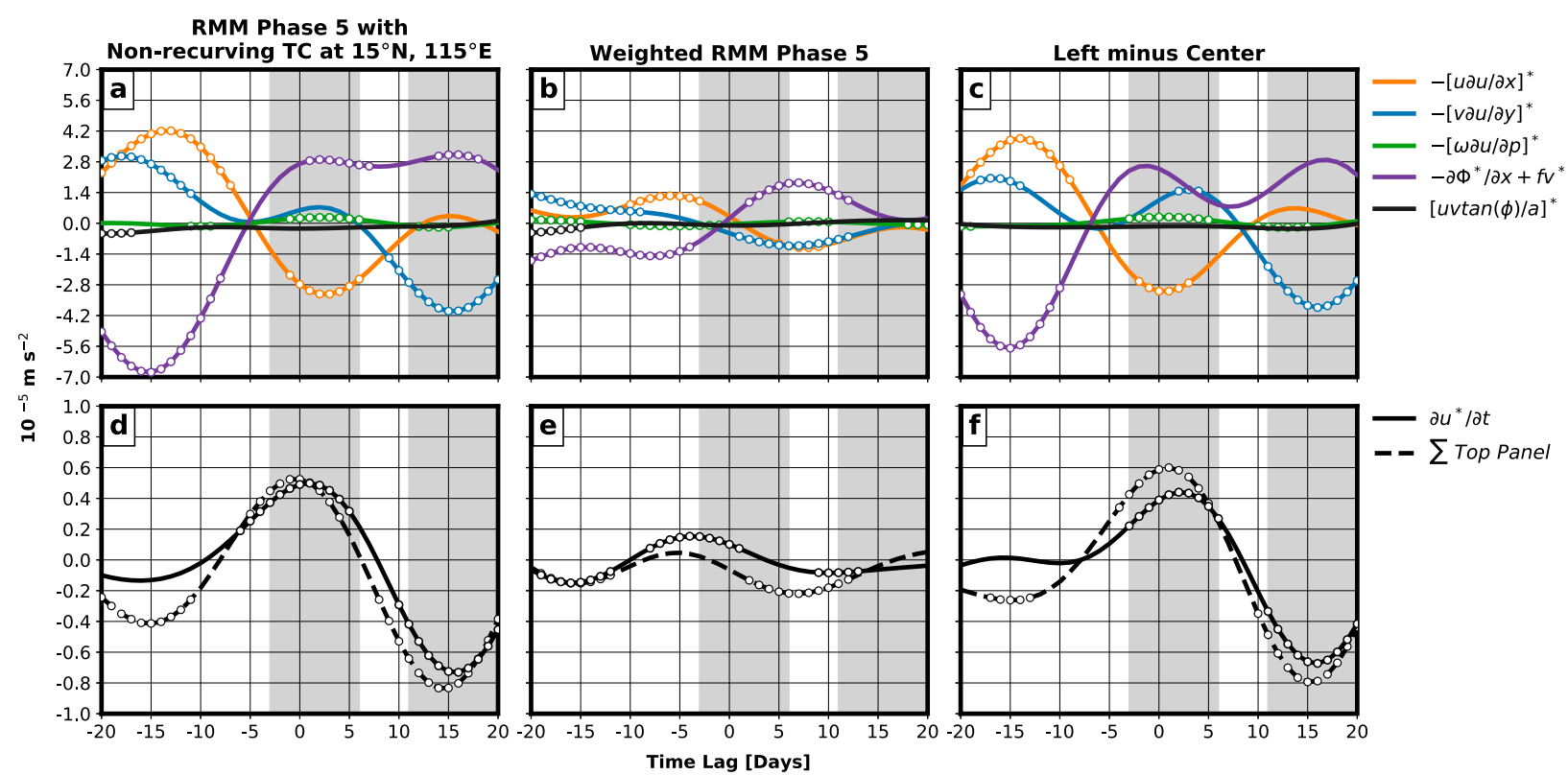

FIG. 4. (a)-(c) Lagged evolution of intraseasonal filtered total advection terms and terms 4 and 5 of (3). (d)-(f) Intraseasonal zonal wind tendency (solid black curve) and the sum of the terms in the top panel of each column (black dashed curve). Columns are ordered as in Fig. 1. Statistically significant values are depicted by unfilled circles. Gray shading highlights time lags in which the intercomposite difference in intraseasonal zonal wind tendency is statistically significant.

Rows represent pentad means that consist of the days indicated along the $y$ axis of their left-column panels. Columns are ordered as in Fig. 1. A positive intraseasonal zonal wind tendency is evident within the averaging box in both composites (Figs. 3a,b,d,e,g,h). Consistent with the results presented in Fig. 2, this signal indicates subtropical jet amplification in response to tropical convective forcing. It achieves greater amplitude in the TCbased composite (Figs. 3a,d,g), and its amplitude differs most from its full population counterpart in the third pentad (Fig. 3i).

To identify which terms on the rhs of (3) contribute most to the amplification of the intraseasonal zonal wind signal in each event set, all terms were averaged across the selected box for a period spanning 20 days before to 20 days after their composite reference dates (lag zero). Figure 4 shows the results of this averaging (note the difference in $y$-axis scale for each row). The bottom row displays the anomalous intraseasonal zonal wind tendency corresponding to the TC-based composite (left), the full population composite (center), and the difference between them (right; solid black curves), along with the sum of all terms in their corresponding top-row panels (dashed black curves). Gray shading in each panel highlights time lags during which the intraseasonal zonal wind tendency in the TC-based composite is statistically significantly different from that in the full population composite, which leads to a focus on 3 days before to 6 days after lag zero. It is during this period that the box-averaged intraseasonal zonal wind tendency peaks at approximately $0.5 \times 10^{-5} \mathrm{~m} \mathrm{~s}^{-2}$ in the TC-based composite (lag zero in Fig. 4d), while it maximizes at a considerably lower value 4-5 days earlier in the full population composite (Fig. 4e). The top row reveals that the TC-based composite tendency is driven primarily by the sum of the intraseasonal zonal pressure (geopotential) gradient force and the Coriolis force acting on the intraseasonal meridional wind (term 4 on the rhs of (3); the purple curve in Fig. 4a), while the corresponding peak in the full population composite is primarily driven by the zonal advection of the zonal wind (orange curve in Fig. 4b). These contributions are statistically significantly different from zero, but their intercomposite differences are not significant (Fig. 4c).

Figure 5 represents the interplay between the background and intraseasonal wind. Terms plotted in Fig. 5a suggest that, for the TC-based composite, the advection of background zonal wind by intraseasonal meridional wind (term $2 b$; dotted blue curve) is another significant contributor to the positive intraseasonal zonal wind tendency shown in Fig. 5d, yet it maximizes more than 5 days after that of its corresponding tendency, which is already declining in amplitude (but still positive), implying that its primary function is to help maintain the strength of the intraseasonal subtropical jet across the averaging box rather than to amplify it. This notion is further supported by its loss in amplitude at the same 

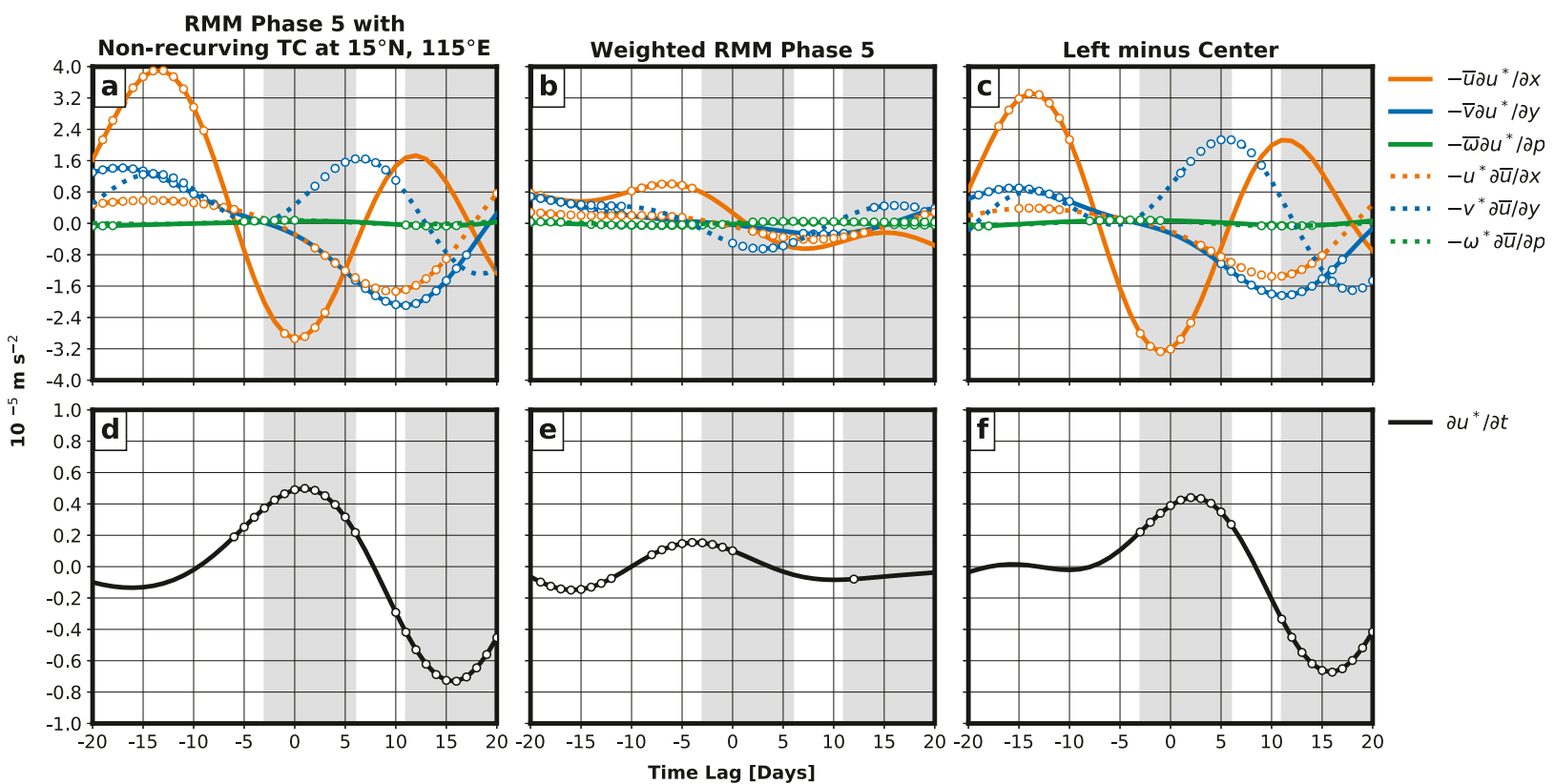

FIG. 5. As in Fig. 4, but for terms 1a, 1b, 2a, 2b, 3a, and 3b of (3). (d)-(f) Only intraseasonal zonal wind tendency is depicted.

time that its corresponding tendency switches sign (approximately 8 days after lag zero). Other terms, like the advection of the background zonal wind by the intraseasonal zonal wind (term $1 \mathrm{~b}$; dotted orange curve in Fig. 5a), occur largely out of phase with term $2 \mathrm{~b}$, thereby offsetting some of its positive contribution to the intraseasonal zonal wind tendency observed in the TC-based composite. In the full population composite, the advection of the intraseasonal zonal wind by the background zonal wind (term 1a; solid orange curve in Fig. 5b) is the dominant momentum source across the averaging box for this set of terms. It is not significantly offset by any comparable advection terms, and it contributes more than $50 \%$ of the amplitude achieved by the zonal advection term in Fig. 4b (solid orange curve), suggesting that it is the primary driver of its associated positive intraseasonal zonal wind tendency (Fig. 5e). It also evolves largely in phase with this

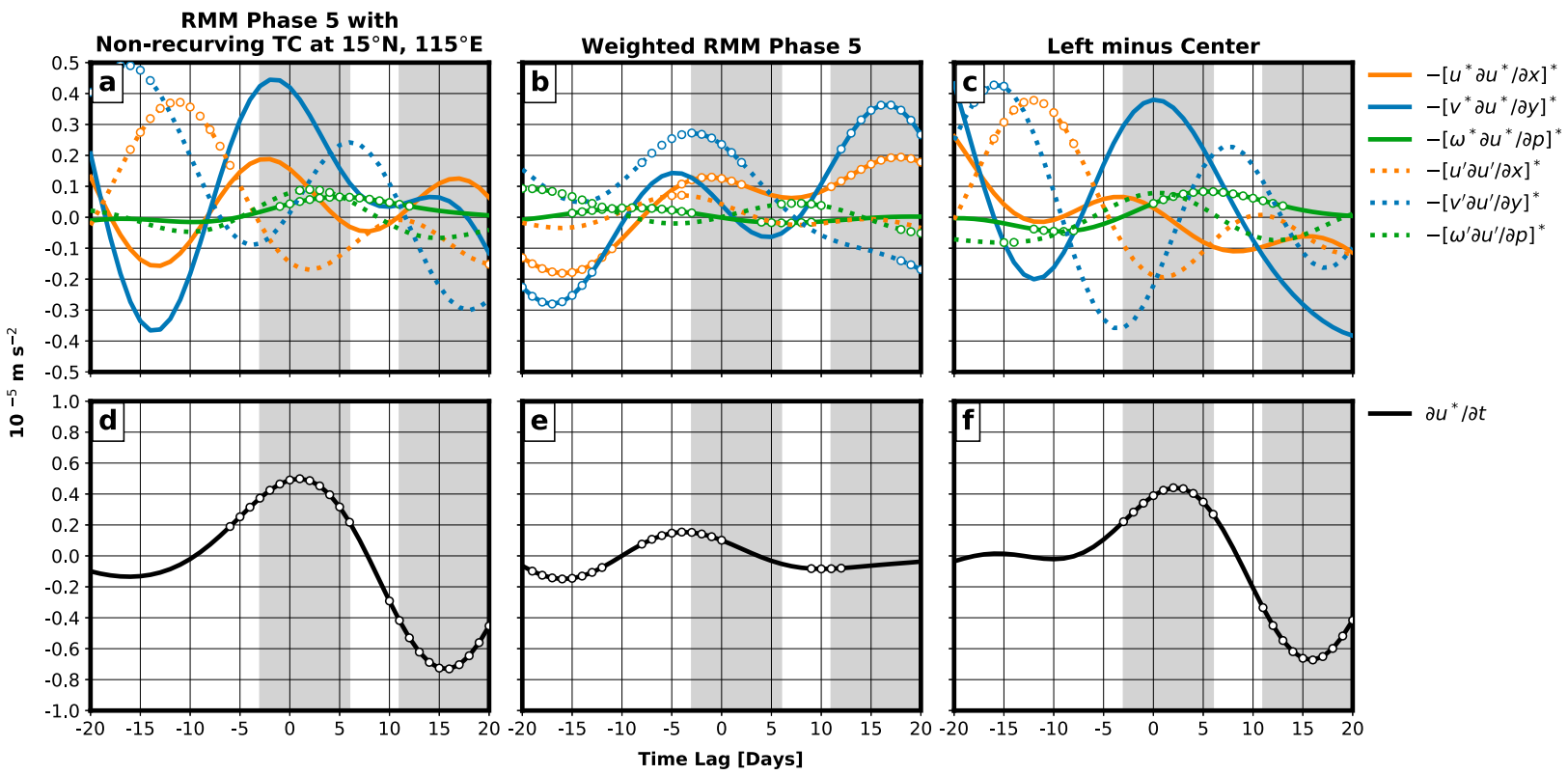

FIG. 6. As in Fig. 4, but for terms 1c, 1d, 2c, 2d, 3c, and 3d of (3). (d)-(f) Only intraseasonal zonal wind tendency is depicted. 
RMM Phase 5 with

Non-recurving $\mathrm{TC}$ at $15^{\circ} \mathrm{N}, 115^{\circ} \mathrm{E}$
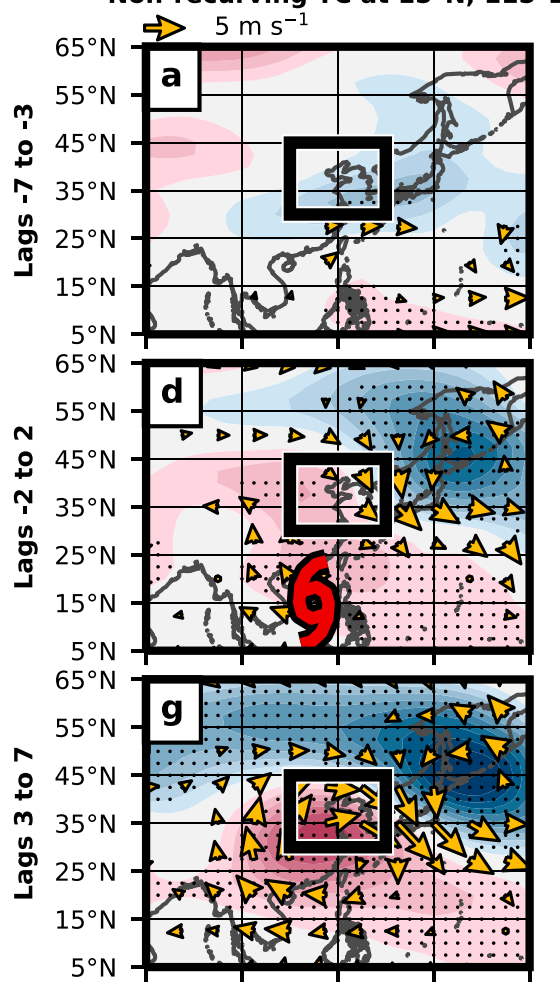

$80^{\circ} \mathrm{E} \quad 100^{\circ} \mathrm{E} \quad 120^{\circ} \mathrm{E} \quad 140^{\circ} \mathrm{E} \quad 160^{\circ} \mathrm{E}$
Weighted RMM Phase 5
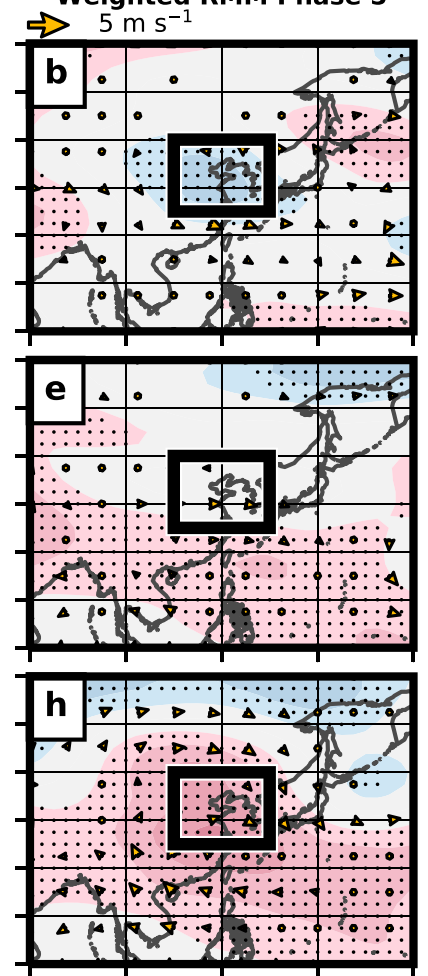

Left minus Center

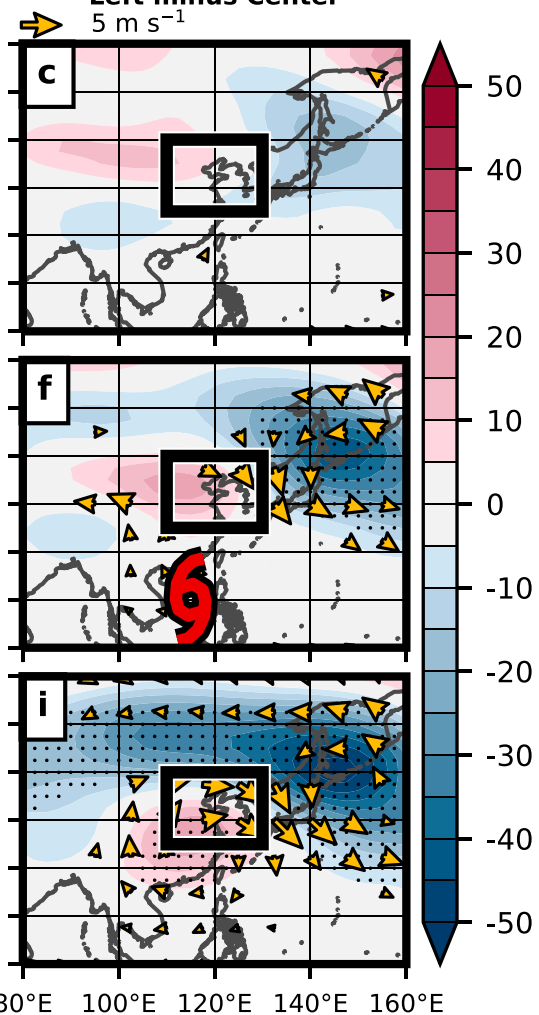

FIG. 7. Pentad-mean intraseasonal filtered 200-hPa geopotential height (color shading; gpm) and vector wind anomalies (yellow vectors; reference vectors are located above the top-left corner of each top-row panel). Pentads correspond to those in Fig. 3. Columns are ordered as in Fig. 1. Statistically significant geopotential height anomalies are stippled. Vectors are only plotted where their corresponding anomalies are statistically significant. The black boxes in each panel outline the averaging box referenced in section 3b(1). (d),(f) Red TC symbols mark the grid point at the center of the search radius used to identify TCs at lag zero.

tendency, implying that it primarily amplifies the intraseasonal subtropical jet streak across the averaging box in the full population composite.

Figure 6 details contributions to the intraseasonal zonal wind tendency by intraseasonal and transient advection terms. Compared to the terms described in the previous two paragraphs, these are relatively small in amplitude when averaged across the selected box. The intraseasonal filtered advection of intraseasonal zonal wind by intraseasonal meridional wind (term 2c; solid blue curve in Fig. 6a) is the largest positive contributor to the intraseasonal zonal wind tendency in the TC-based composite when this tendency is positive and amplifying (Fig. 6d), yet neither it nor its intercomposite difference achieve statistical significance. Other intraseasonal advection terms (i.e., terms $1 \mathrm{c}$ and $3 \mathrm{c}$; solid orange and green curves in Fig. 6a) in the TC-based composite are even smaller than term $2 \mathrm{c}$, thus appearing physically irrelevant to the evolution of intraseasonal zonal wind within the averaging box. Transient advection terms (dotted curves in Figs. 6a,b) are of greater interest because they represent zonal momentum accelerations that are forced by circulation components whose evolutionary time scales match those of TCs, so they include direct TC contributions to intraseasonal zonal wind acceleration. Surprisingly, none of these terms achieve statistical significance in the TC-based composite when the intraseasonal zonal wind tendency is positive and amplifying inside the averaging box, and they are also small relative to the largest positively contributing term in this set (term $2 \mathrm{c})$. In the full population composite, the intraseasonal filtered advection of transient zonal wind by transient meridional wind (term 2d; dotted blue curve in Fig. 6b) is statistically significant and maximizes in phase with its associated tendency (Fig. 6e), which suggests that it amplifies the intraseasonal zonal wind signal within the averaging box.

\section{2) RELATIONSHiP TO TC PRESENCE}

The results in Fig. 6a give the impression that TCs do not yield any significant contributions to the intraseasonal zonal wind tendency in the TC-based 
RMM Phase 5 with

Non-recurving TC at $15^{\circ} \mathrm{N}, 115^{\circ} \mathrm{E}$
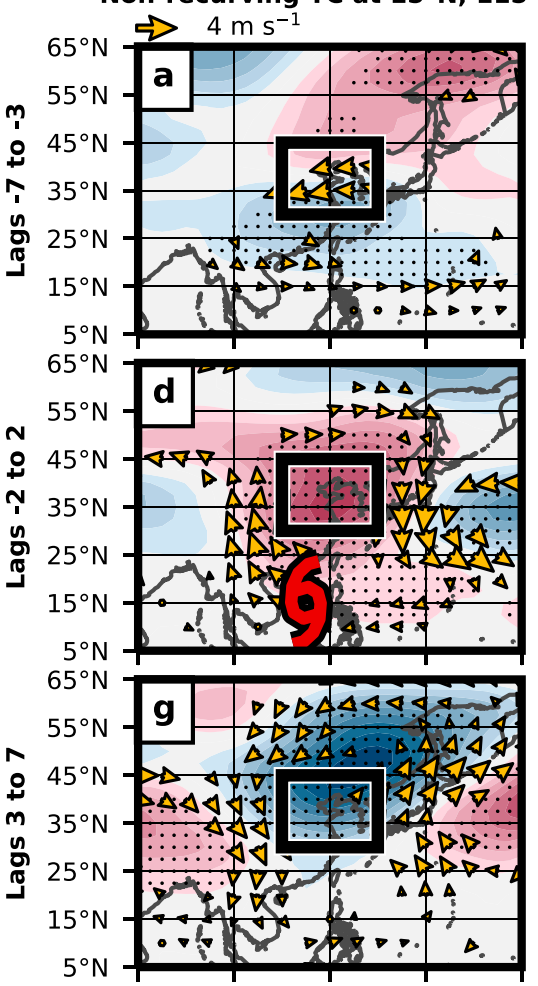

Weighted RMM Phase 5
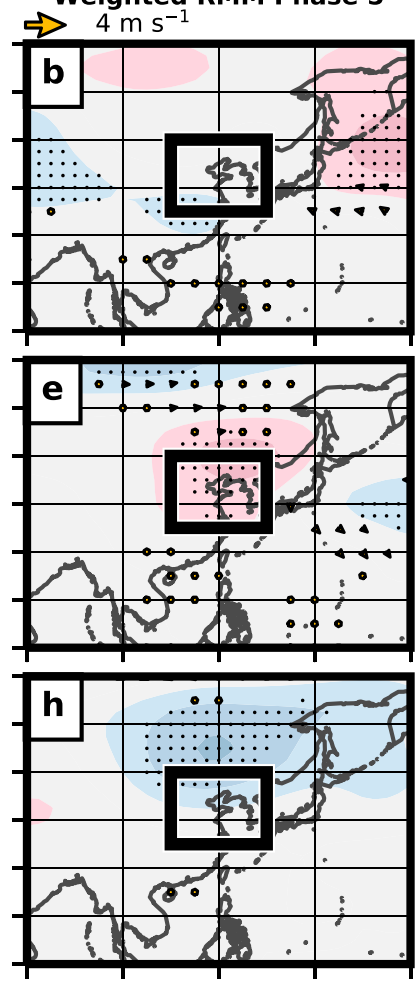

Left minus Center

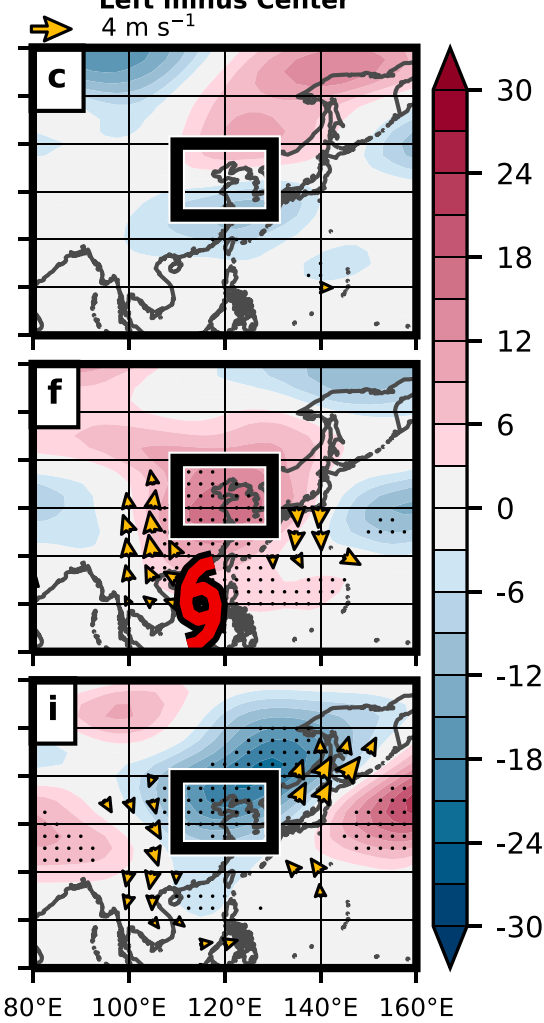

FIG. 8. As in Fig. 7, but for transient filtered 200-hPa geopotential height and vector wind anomalies.

composite because all transient advection terms averaged across the selected box are small and not statistically significant. In reality, these terms, to which TCs can directly contribute to the signal, significantly modulate the upper-level intraseasonal zonal momentum budget across East Asia and the adjacent northwest Pacific Ocean, especially in the early stages of East Asian subtropical jet amplification. Figure 7 shows this jet amplification in each composite by overlaying pentadmean $200-\mathrm{hPa}$ intraseasonal vector wind anomalies on intraseasonal geopotential height anomalies at the same level (pentads and columns correspond to those in Fig. 3). Anomaly patterns associated with each composite are statistically indistinguishable from one another in the first pentad (Figs. 7a-c). Significant differences between the two composites emerge over East Asia and the adjacent northwest Pacific Ocean during the second pentad as an anomalous intraseasonal extratropical Rossby wave train takes form in the TC-based composite (Figs. 7d-f). These differences appear directly linked to enhanced convection, partly related to the composite TC, positioned over the Maritime Continent and South China Sea in the TC-based composite (not shown), which manifests as a statistically significant channel of anomalous southerly flow directed from this region toward the averaging box. No analogous signal is present in the full population composite. An even more pronounced northwest-southeast-oriented channel of intraseasonal vector wind anomalies develops over Japan (Figs. 7d,f), signaling the amplification of the aforementioned intraseasonal subtropical jet streak. These wind anomalies grow in tandem with the amplifying height field through the third pentad and achieve greater amplitude in the TC-based composite (Figs. 7g-i).

A similar set of analyses is presented in Fig. 8 to examine the evolution of the transient component of the large-scale circulation. An anomalous transient upperlevel anticyclone emerges poleward of the composite TC. Figures $8 \mathrm{~d}$ and $8 \mathrm{f}$ suggest that its formation is partly associated with diabatically driven upper-level outflow (indicated by a channel of yellow vectors poleward from the TC symbol) linked to enhanced convection coincident with or proximate to the TC. The full population composite has no comparable signal (Fig. 8e). An equatorward-propagating transient upper-level extratropical Rossby wave train (Fig. 9) also contributes to the development of this circulation anomaly 


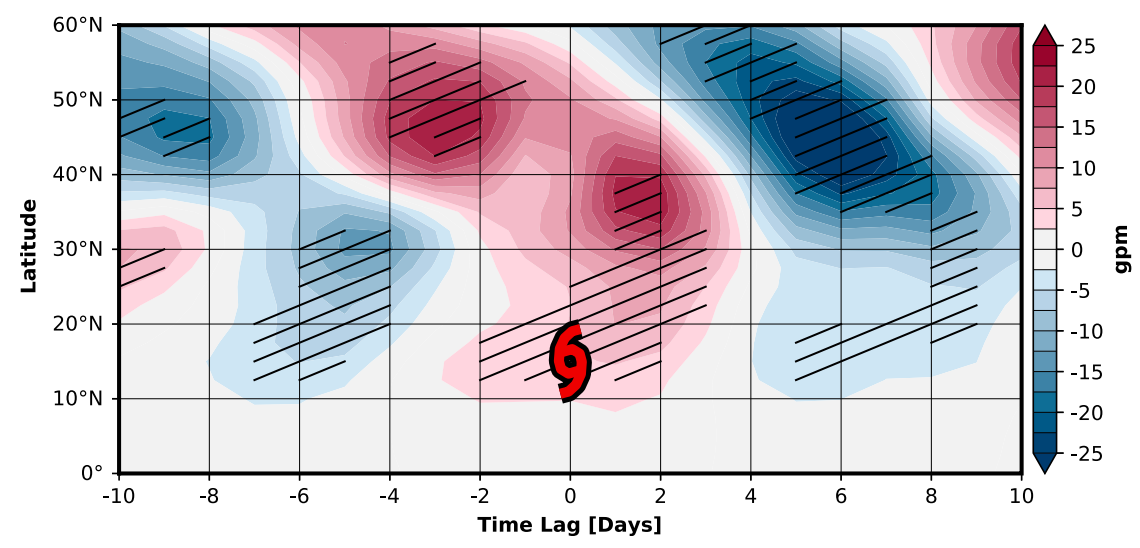

FIG. 9. A time-latitude diagram of transient filtered 200-hPa geopotential height anomalies (color shading; gpm) averaged between $120^{\circ}$ and $140^{\circ} \mathrm{E}$. Statistically significant anomalies are hatched. The red TC symbol marks the center of the TC search radius in time and latitude.

in the TC-based composite, and this signal is present in a weakened state in the full population composite (not shown). When the extratropical portion of the aforementioned circulation anomaly reaches equatorward of approximately $40^{\circ} \mathrm{N}$, it constructively interferes with a poleward-propagating same-signed circulation anomaly that accompanies a poleward-dispersing transient wave train (Fig. 9). No analogous signal is present in the full population composite (not shown). A portion of this poleward-oriented signal is contributed by the composite TC, which is embedded within a transient westward-propagating wave packet (Fig. 10a). There is a hint of this westward-evolving wave signal in the full population composite (Fig. 10b), but it is weaker than in the TC-based composite and generally not statistically significant.

Consolidation of the tropical and extratropical components of the transient upper-level anomalous anticyclone poleward of the composite TC yields a strengthening of this circulation feature and a meridional elongation of its structure relative to that in the full population composite (Figs. 8d-i). Its phasing with the intraseasonal circulation allows it to advect transient westerly momentum equatorward on its eastern flank and deposit it into the growing intraseasonal subtropical jet streak over Japan, thereby contributing positive intraseasonal zonal wind acceleration to the amplifying jet (Fig. 11d). There is no clear association between transient advection and intraseasonal zonal wind acceleration in the full population composite (Fig. 11e). Several days later, following TC passage, an anomalous transient upper-level cyclone supplants the anticyclone partly because of a reduction in transient latent heat release to its south (not shown). Counterclockwise flow around it yields intraseasonal westerly wind acceleration through the jet streak in association

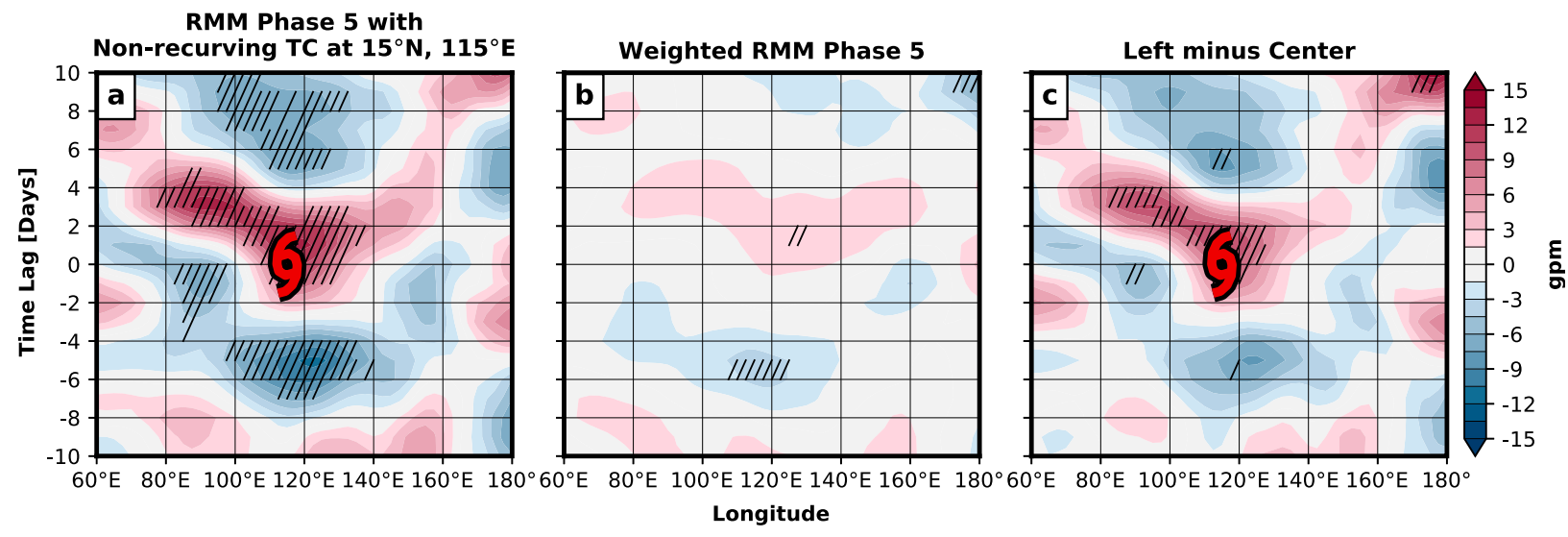

FIG. 10. Longitude-time diagrams of transient filtered 200-hPa geopotential height anomalies (color shading; gpm) averaged between $15^{\circ}$ and $30^{\circ} \mathrm{N}$. Columns are ordered as in Fig. 1. Statistically significant anomalies are hatched. (a),(c) The red TC symbols mark the center of the TC search radius in time and longitude. 
RMM Phase 5 with
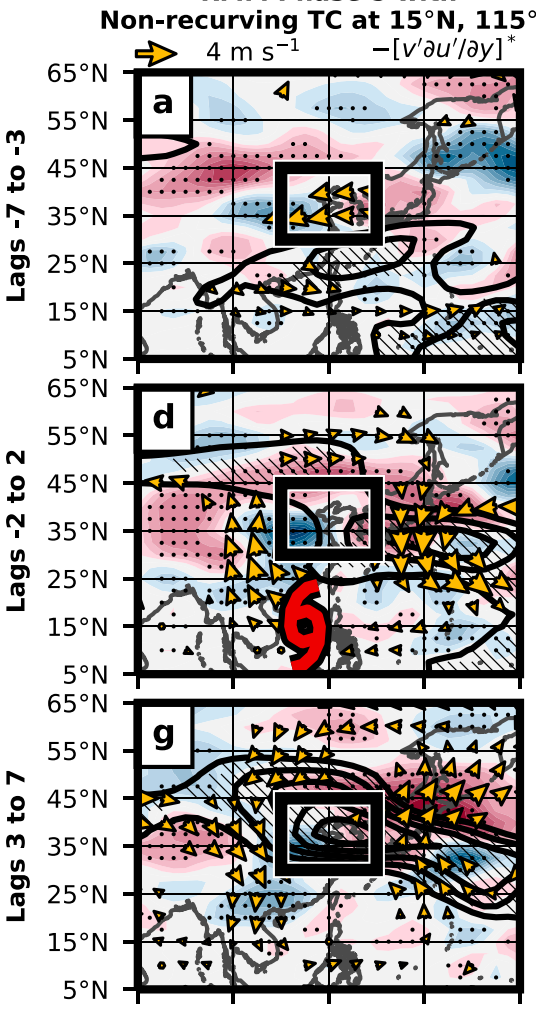

$80^{\circ} \mathrm{E} \quad 100^{\circ} \mathrm{E} \quad 120^{\circ} \mathrm{E} \quad 140^{\circ} \mathrm{E} \quad 160$
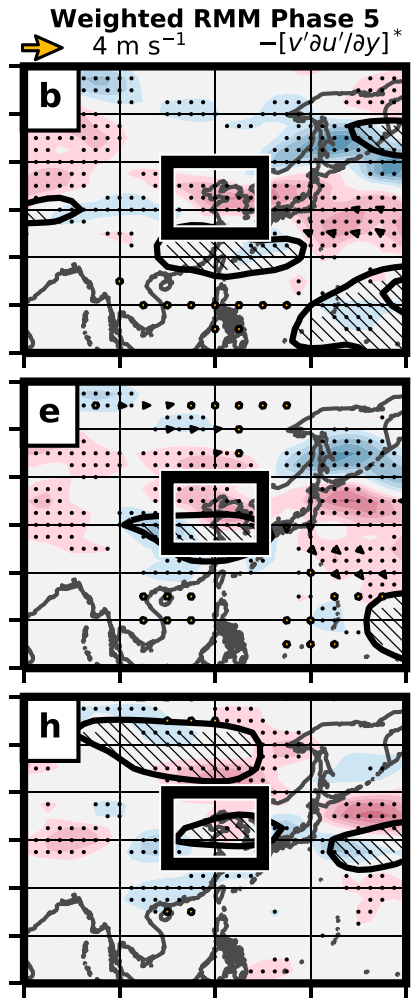

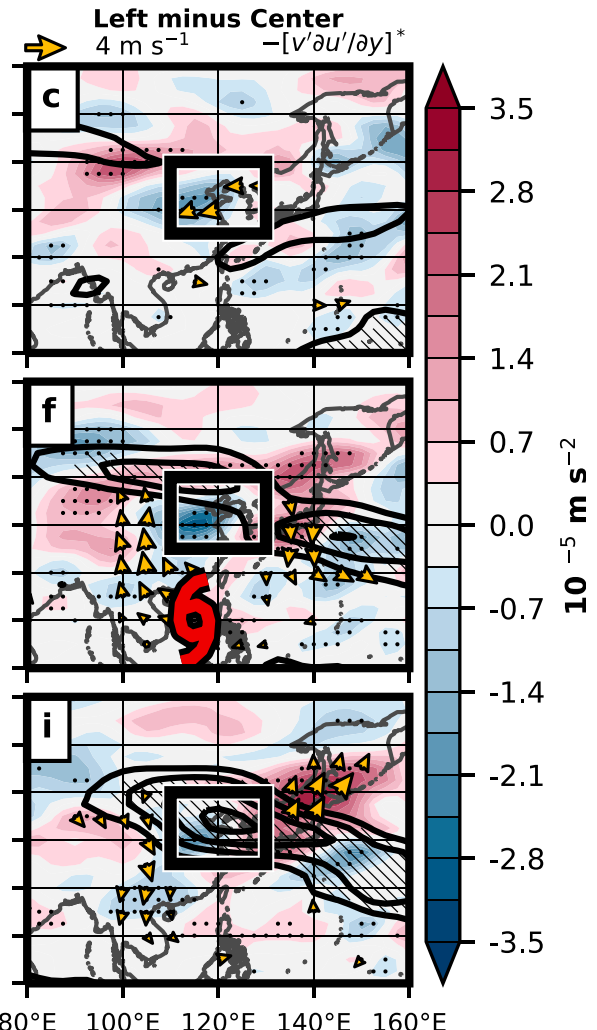

FIG. 11. Pentad-mean intraseasonal filtered advection of transient zonal wind by transient meridional wind (term $2 \mathrm{~d}$; color shading; $1 \times 10^{5} \mathrm{~m} \mathrm{~s}^{-2}$; labeled above the top-right corner of each top-row panel) transient vector wind anomalies (yellow vectors in $\mathrm{m} \mathrm{s}^{-1}$; reference vectors are located above the top-left corner of each top-row panel), and intraseasonal filtered 200-hPa zonal wind anomalies (black contours; $\mathrm{m} \mathrm{s}^{-1}$; only positive anomalies are shown; contour interval is $1 \mathrm{~m} \mathrm{~s}^{-1}$ ). Pentads correspond to those in Fig. 3. Columns are ordered as in Fig. 1. Statistically significant term values are stippled, and statistically significant zonal wind anomalies are hatched. Vectors are plotted where their corresponding anomalies are statistically significant. The black boxes in each panel outline the averaging box referenced in section 3b(1). (d), (f) Red TC symbols mark the grid point at the center of the search radius used to identify TCs at lag zero.

with the poleward advection of transient westerly momentum on its eastern flank (Fig. 11g). Once again, no analogous signal is present in the full population composite (Fig. 11h). Removing the term that describes these accelerations (term 2d) from the rhs of (3) yields a net negative intraseasonal zonal wind tendency across the amplifying subtropical jet streak over Japan (not shown), implying that the jet streak would decelerate in its absence. This same process was performed separately for the other two transient advection terms (terms 1d and $3 \mathrm{~d}$ ) to assess their relative importance to the growth of the positive intraseasonal zonal wind signal across East Asia. In neither case did their removal yield a significant change in intraseasonal zonal wind tendency through the amplifying East Asian subtropical jet streak (not shown). These results suggest that the transient meridional advection of transient zonal wind is the most physically relevant transient (TC scale) advection term to the intraseasonal zonal wind acceleration observed across Japan and the adjacent northwest Pacific Ocean in the TC-based composite.

\section{3) JET MAINTENANCE}

The intraseasonal subtropical jet streak that emerges over East Asia and the adjacent northwest Pacific Ocean is maintained by additional momentum sources that operate on different time scales. The two largest of these sources are addressed herein. Figure 12 relates intraseasonal zonal wind acceleration to a transfer of zonal momentum from background to intraseasonal time scales (term 2b). Since the background wind acts as a constant momentum source on intraseasonal time scales, it accelerates the intraseasonal zonal wind when it is advected from higher to lower values by the intraseasonal wind. Figures $12 \mathrm{a}, 12 \mathrm{~d}$, and $12 \mathrm{~g}$ depict these positive accelerations through and to the 

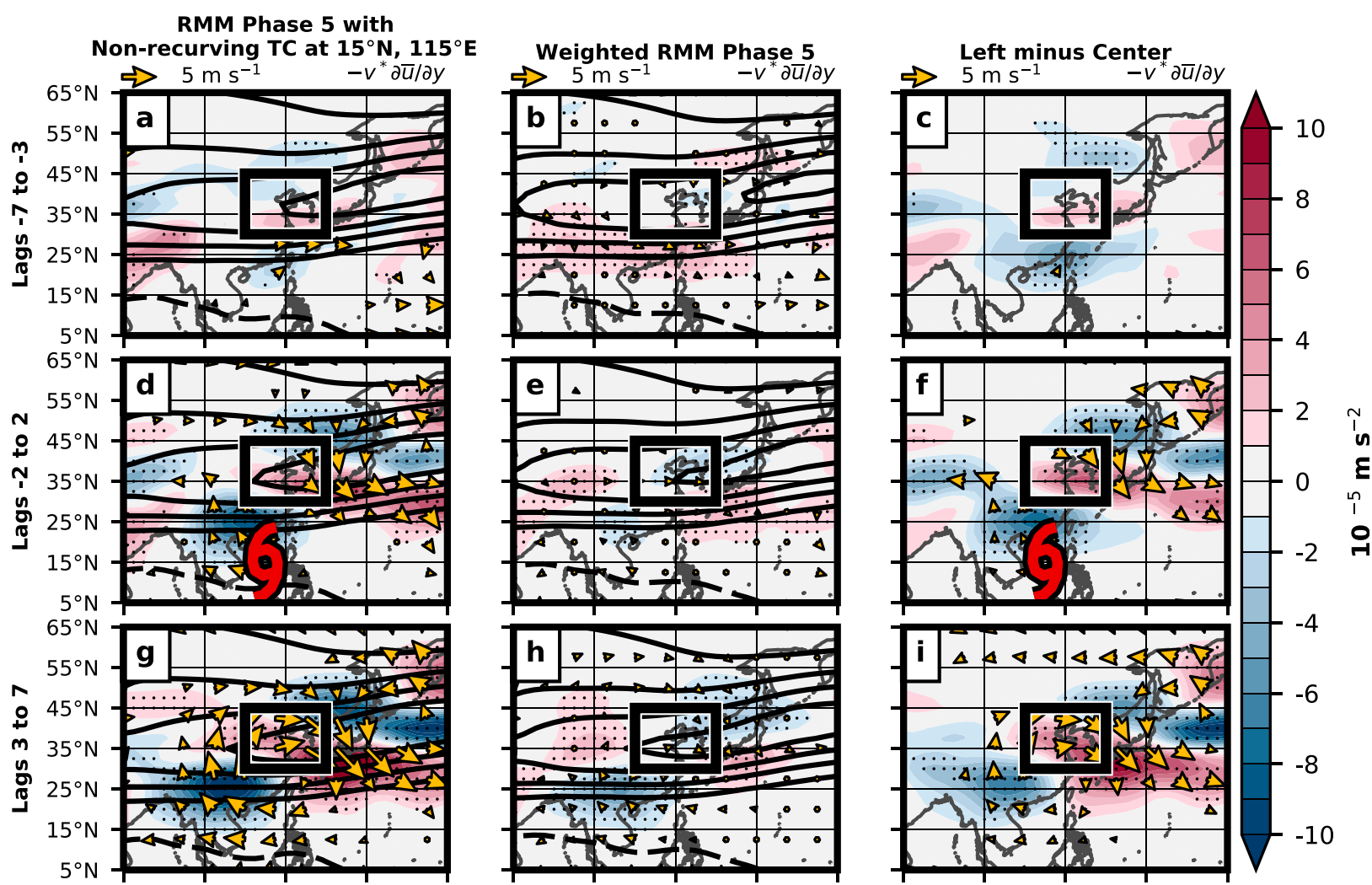

$80^{\circ} \mathrm{E} \quad 100^{\circ} \mathrm{E} \quad 120^{\circ} \mathrm{E} \quad 140^{\circ} \mathrm{E} \quad 160^{\circ} \mathrm{E} \quad 80^{\circ} \mathrm{E} \quad 100^{\circ} \mathrm{E} \quad 120^{\circ} \mathrm{E} \quad 140^{\circ} \mathrm{E} \quad 160^{\circ} \mathrm{E} \quad 80^{\circ} \mathrm{E} \quad 100^{\circ} \mathrm{E} \quad 120^{\circ} \mathrm{E} \quad 140^{\circ} \mathrm{E} \quad 160^{\circ} \mathrm{E}$

FIG. 12. Pentad-mean $200-\mathrm{hPa}$ advection of the background zonal wind by the intraseasonal meridional wind (term $2 \mathrm{~b}$; color shading; $1 \times 10^{5} \mathrm{~m} \mathrm{~s}^{-2}$; labeled above the top-right corner of each top-row panel), intraseasonal vector wind anomalies (yellow vectors; $\mathrm{m} \mathrm{s}^{-1}$; reference vectors are located above the top-left corner of each top-row panel), and the background zonal wind (black contours; $\mathrm{m} \mathrm{s}^{-1}$; solid contours indicate positive values; contour interval is $10 \mathrm{~m} \mathrm{~s}^{-1}$, beginning at $\pm 10 \mathrm{~m} \mathrm{~s}$ ). Pentads correspond to those in Fig. 3. Columns are ordered as in Fig. 1. Statistically significant term values are stippled. Vectors are plotted where their corresponding anomalies are statistically significant. The black boxes in each panel outline the averaging box referenced in section $3 b(1)$. (d),(f) Red TC symbols mark the grid point at the center of the search radius used to identify TCs at lag zero.

southeast of the averaging box in the TC-based composite. Their growth coincides with the advection of higher values of background zonal wind toward lower values by the intraseasonal meridional wind. A similar signal is present in the full population composite, but its placement differs slightly from that in the TC-based composite, and it attains lower amplitude (Figs. 12b,e,h). This acceleration mechanism couples with that associated with the meridional advection of transient zonal wind described in the previous subsection to accelerate and maintain the intraseasonal subtropical jet in the TC-based composite. Their simultaneous contributions to intraseasonal zonal wind acceleration are shown in Fig. 13. Positive acceleration induced by the meridional advection of transient zonal wind (term 2d; gold curve) peaks about 5 days after its corresponding zonal wind tendency maximizes (black curve) and about 4 days prior to when peak positive acceleration is achieved by the advection of background zonal wind by the intraseasonal meridional wind (term $2 b$; blue curve). The intraseasonal subtropical jet streak begins to decelerate (it crosses the zero line along the $y$ axis) immediately after term $2 \mathrm{~b}$ maximizes, suggesting that this term is a primary contributor to intraseasonal jet-streak maintenance, whereas term $2 \mathrm{~d}$ contributes more to jet-streak amplification.

Injection of westerly momentum into the intraseasonal subtropical jet streak depicted in the TC-based composite yields a departure from geostrophic balance, so a mass field adjustment must occur in order to restore balance. To aid in visualizing this process, Fig. 14 overlays intraseasonal filtered $200-\mathrm{hPa}$ geopotential height and vector wind anomalies on term 4 (the sum of the intraseasonal pressure gradient force and the Coriolis torque on the intraseasonal meridional wind). The Coriolis force contained in term 4 responds to this 


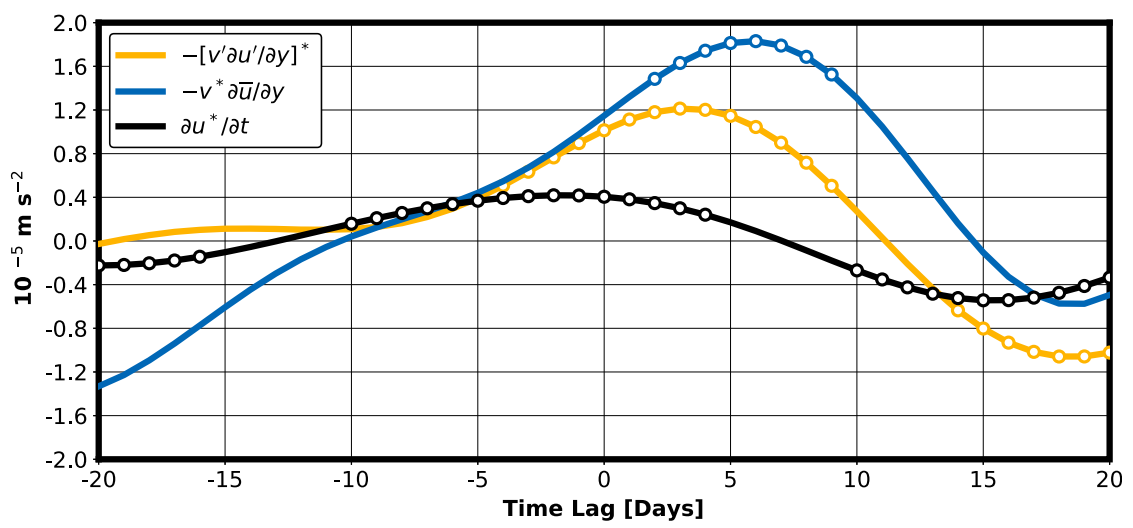

FIG. 13. The lagged evolution of the intraseasonal filtered $200-\mathrm{hPa}$ advection of transient zonal wind by transient meridional wind (term $2 \mathrm{~d}$; golden curve), the $200-\mathrm{hPa}$ advection of background zonal wind by intraseasonal meridional wind (term $2 \mathrm{~b}$; blue curve), and 200-hPa intraseasonal zonal wind tendency (black curve). Values are computed across a domain bounded to the west and east by $120^{\circ}$ and $140^{\circ} \mathrm{E}$ and bounded to the north and south by $30^{\circ}$ and $45^{\circ} \mathrm{N}$. Statistically significant values are indicated by unfilled circles.

departure by building easterly acceleration over Japan (concomitant with the subtropical jet streak) that transfers mass from the trough centered on the Kamchatka Peninsula to the developing subtropical ridge over China, thereby amplifying this ridge and deepening the trough to its northeast, and increasing the horizontal geopotential gradient between them (Figs. 14d,g). This Coriolis-driven acceleration is illustrated in Fig. 15 and is evident in both composites. As the mass field adjusts, the subtropical jet on the poleward flank of the amplifying subtropical ridge accelerates in response to the strengthening geopotential gradient. This process is most evident in the TC-based composite (e.g., Fig. 14g), wherein larger westerly wind accelerations occur as momentum responds to greater mass adjustment than in the full population composite. A portion of this acceleration is facilitated by the advection of background zonal wind by intraseasonal meridional wind (Fig. 12g), as well as by the intraseasonal component of the advection of the intraseasonal zonal wind by the intraseasonal meridional wind (not shown). Upper-level outflow associated with tropical convection over the Maritime Continent and South China Sea (not shown) aids in this process by redistributing mass and momentum from the tropics to higher latitudes.

\section{c. Subsequent intraseasonal extratropical circulation progression}

Prior to delving into the mechanisms that influence the intraseasonal zonal wind progression across the rest of the North Pacific Ocean and North America, the disparity between the two composites with reference to the strength of their extratropical Rossby wave responses is considered. Vorticity advection is a common framework through which to assess the Rossby wave response to anomalous tropical heating (e.g., Sardeshmukh and Hoskins 1988; Jin and Hoskins 1995; Lukens et al. 2017). When a tropical heating anomaly is imposed, a Rossby wave source (RWS) grows poleward of the anomalous heating in response to horizontal vorticity advection by the anomalous divergent wind that is forced by the heat source. Poleward vorticity advection strengthens the horizontal vorticity gradient that maximizes in the subtropics. It is along this vorticity gradient that the subtropical jet resides, and its strength is proportional to the strength of this gradient. Rotational flow anomalies that manifest as upper-level cyclones or anticyclones poleward of anomalous heating (depending on the sign of the heating anomaly) eventually form in association with the meridional displacement of vorticity. This represents one pathway through which to link the previously described momentum anomalies to anomalous tropical convection, although it does not directly address momentum growth sources via scale interactions.

Sardeshmukh and Hoskins (1988) demonstrated that the strength of the RWS is proportional to the local horizontal vorticity gradient to which it is tied. Given the association between the strength of this vorticity gradient and that of the subtropical jet, a stronger subtropical jet response indicates a stronger RWS and portends a more amplified extratropical Rossby wave response. Lukens et al. (2017) demonstrated that vorticity anomalies that form in conjunction with horizontal vorticity advection by the divergent wind are advected downstream by the climatological jet and 

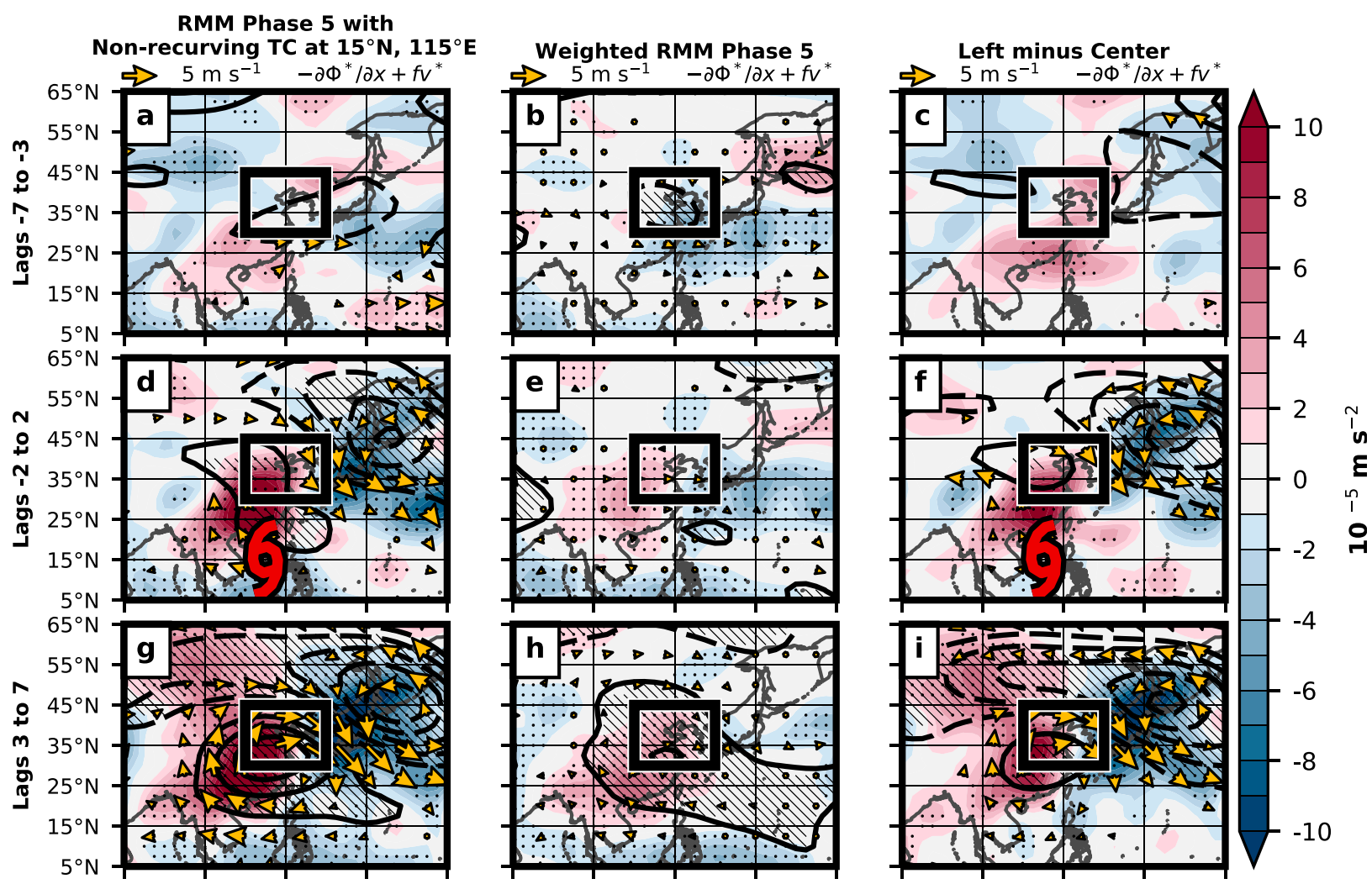

$80^{\circ} \mathrm{E} \quad 100^{\circ} \mathrm{E} \quad 120^{\circ} \mathrm{E} \quad 140^{\circ} \mathrm{E} \quad 160^{\circ} \mathrm{E} \quad 80^{\circ} \mathrm{E} \quad 100^{\circ} \mathrm{E} \quad 120^{\circ} \mathrm{E} \quad 140^{\circ} \mathrm{E} \quad 160^{\circ} \mathrm{E} \quad 80^{\circ} \mathrm{E} \quad 100^{\circ} \mathrm{E} \quad 120^{\circ} \mathrm{E} \quad 140^{\circ} \mathrm{E} \quad 160^{\circ} \mathrm{E}$

FIG. 14. Pentad-mean 200-hPa sum of the pressure (geopotential) gradient force and Coriolis torque on the intraseasonal meridional wind (term 4; color shading; $1 \times 10^{5} \mathrm{~m} \mathrm{~s}^{-2}$; labeled above the top-right corner of each top-row panel), intraseasonal filtered 200-hPa geopotential height anomalies (black contours; gpm; solid contours indicated positive anomalies; contour interval is $10 \mathrm{gpm}$, beginning at $\pm 10 \mathrm{gpm}$ ), and intraseasonal vector wind anomalies (yellow vectors; $\mathrm{m} \mathrm{s}{ }^{-1}$; reference vectors are located above the top-left corner of each top-row panel). Pentads correspond to those in Fig. 3. Columns are ordered as in Fig. 1. Statistically significant term values are stippled, and statistically significant geopotential height anomalies are hatched. Vectors are plotted where their corresponding anomalies are statistically significant. The black boxes in each panel outline the averaging box referenced in section 3b(1). (d), (f) Red TC symbols mark the grid point at the center of the search radius used to identify TCs at lag zero.

disperse into the extratropics when they reach its exit region, where the vorticity gradient coincident with the jet weakens to the point that they are able to amplify out of the subtropics (see their Fig. 12). They, too, noted that the strength of the Rossby wave response depends on the strength of the horizontal vorticity advection associated with upper-level divergent wind anomalies linked to anomalous tropical heating. Following this logic, it is not surprising that the Rossby wave response in the TC-based composite is much stronger than that in the full population composite. Indeed, horizontal (potential) vorticity (PV) advection by the divergent wind (e.g., Archambault et al. 2013) achieves higher amplitude in the TC-based compositeit is dominated by the advection of background PV by the intraseasonal divergent wind (Fig. 16), but transient PV advection (not shown) is its second largest contributor-which relates to its associated convection being locally more intense than in the full population composite (not shown). In fact, differences in PV advection between the two composites are maximized inside the averaging box, exactly where the intraseasonal zonal wind maximizes. These differences originate in association with the establishment of a stronger horizontal intraseasonal PV gradient in the TC-based composite (not shown).

Figure 17 illustrates the life cycle of the anomalous intraseasonal extratropical Rossby wave train in the TC-based composite and includes the large-scale intraseasonal flow evolution accompanying the full population composite for comparison. Its transformation is depicted by four consecutive pentad means of intraseasonal $200-\mathrm{hPa}$ geopotential height and vector wind anomalies. The background zonal wind at the 


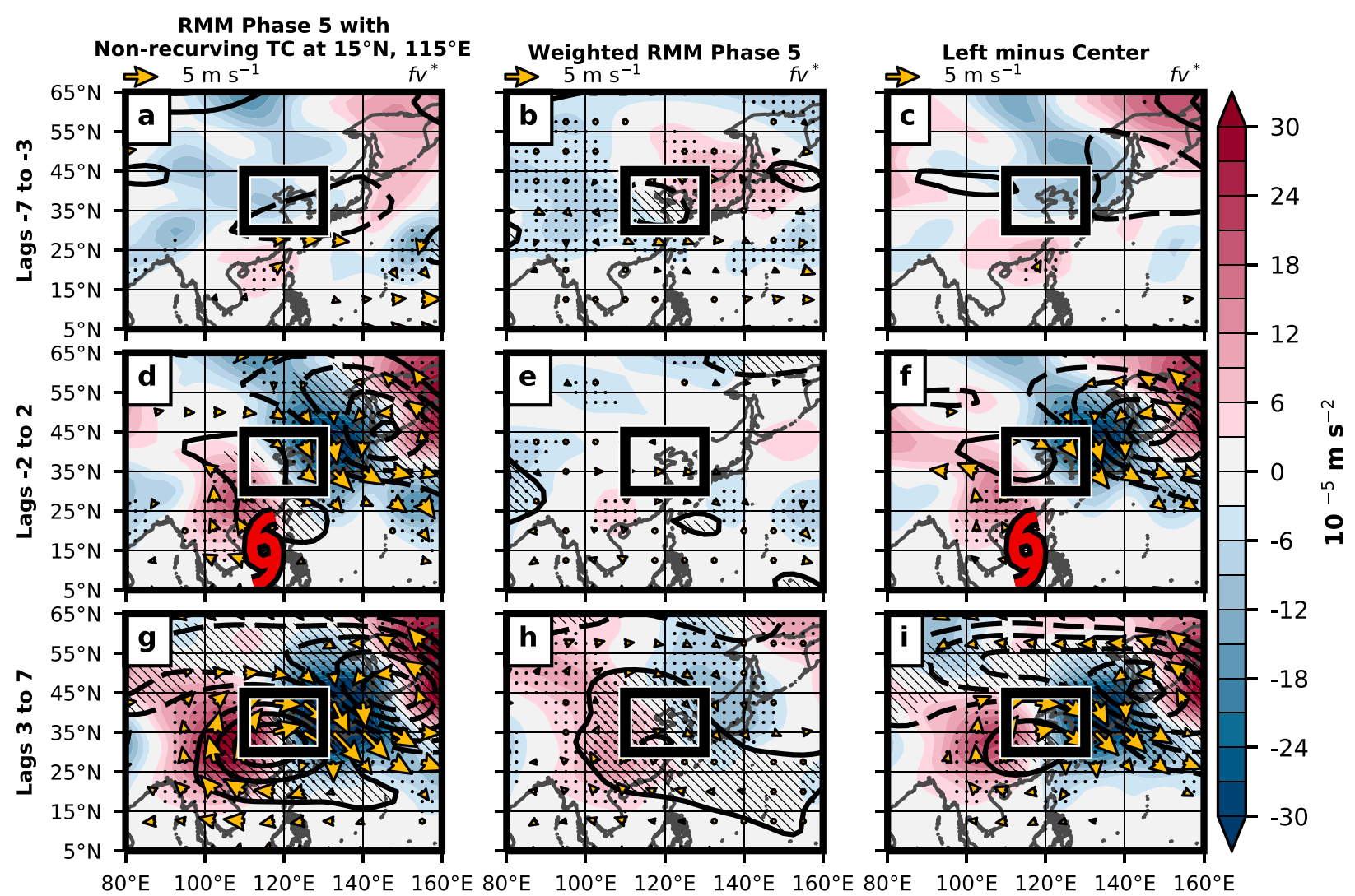

FIG. 15. As in Fig. 14, but for only the Coriolis torque component of term 4.

same level is also overlaid in black contours. In the first two pentads (Figs. 17a,c), the wave train extends from subtropical East Asia to the northwest Atlantic and possesses a wavenumber-4 structure. Stepping forward one pentad (Fig. 17e), the subtropical anticyclone over East Asia has weakened and retrograded, as has the subtropical jet response on its poleward flank. This evolution marks a decay and retrogression of the RWS discussed in the previous two paragraphs (not shown), which occurs as the convectively active phase of the ER wave propagates westward and decays, and its trailing convectively suppressed phase intersects MJO convection (also not shown). The extratropical Rossby wave response tied to this convective forcing flattens as convection weakens, and a surge of westerly momentum develops across the North Pacific. By the last pentad (Fig. 17g), a broad intraseasonal ridge anomaly is present across eastern North America, and a broad intraseasonal trough anomaly is located to its west. The large-scale circulation in the full population composite evolves much more gradually than in the TC-based composite, with steady Rossby wave dispersion evident across all four pentads (Figs. 17b,d,f,h). In this case, the intraseasonal subtropical jet does not undergo a rapid metamorphosis across the lag window, so no associated intraseasonal westerly wind surge occurs.

The aforementioned TC-based composite westerly wind surge originates in association with several moving parts. Two of its largest forcing terms are shown in Figs. 18 and 19 . The superposition of the intraseasonal and background zonal winds yields westerly intraseasonal zonal wind acceleration east of the date line, between $30^{\circ}$ and $45^{\circ} \mathrm{N}$, as the intraseasonal meridional wind advects higher values of background westerly wind equatorward (Figs. 18a-c). This process is also evident to the south of Japan (Figs. 18a,b) in association with clockwise flow around the anomalous upper-level intraseasonal subtropical anticyclone anchored by western North Pacific tropical convection to its south (not shown). As convection decays, its associated extratropical Rossby wave response flattens. The anomalous upper-level anticyclone positioned over the central North Pacific (denoted by its clockwise circulation in the vector field in Figs. 18a,b) sinks equatorward and grows in zonal extent. This evolution is supported in part by westerly intraseasonal zonal wind acceleration on its equatorward flank, easterly acceleration to the south of that, and easterly acceleration on its poleward 

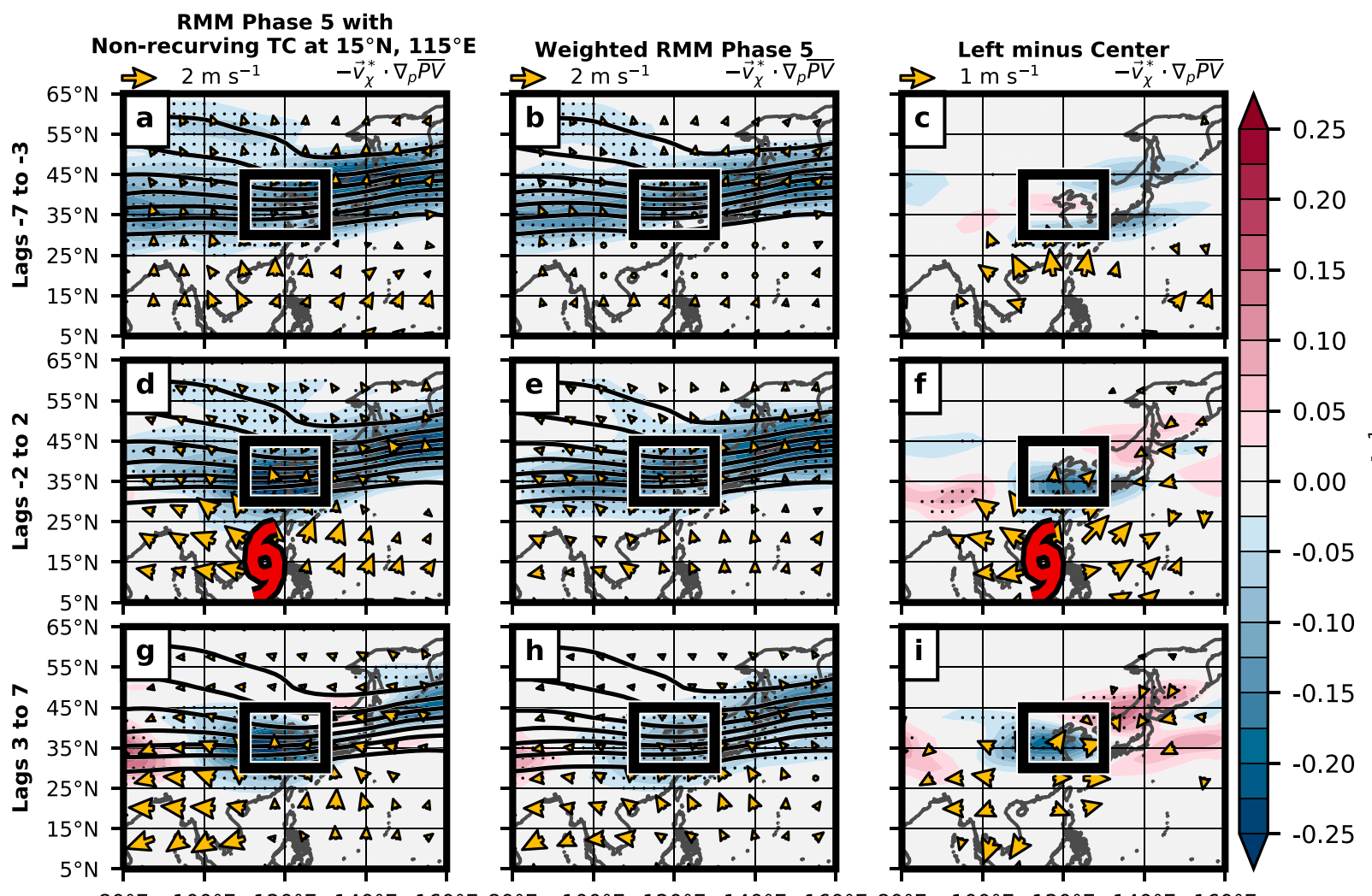

\section{3}
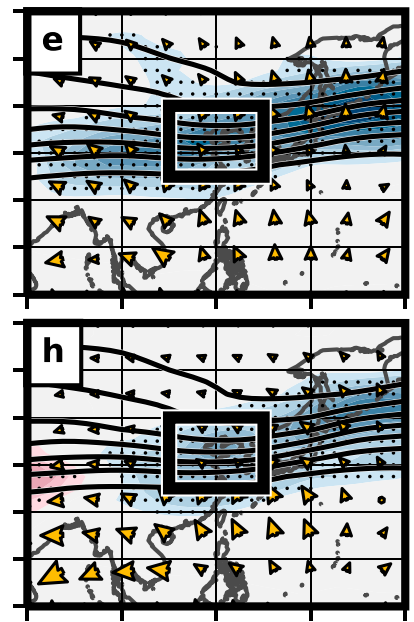

$80^{\circ} \mathrm{E} \quad 100^{\circ} \mathrm{E} \quad 120^{\circ} \mathrm{E} \quad 140^{\circ} \mathrm{E} \quad 160^{\circ} \mathrm{E} \quad 80^{\circ} \mathrm{E} \quad 100^{\circ} \mathrm{E} \quad 120^{\circ} \mathrm{E} \quad 140^{\circ} \mathrm{E} \quad 160^{\circ} \mathrm{E} \quad 80^{\circ} \mathrm{E} \quad 100^{\circ} \mathrm{E} \quad 120^{\circ} \mathrm{E} \quad 140^{\circ} \mathrm{E} \quad 160^{\circ} \mathrm{E}$

FIG. 16. Pentad-mean 200-hPa horizontal advection of background PV by the intraseasonal divergent wind [color shading; PVU day ${ }^{-1}$ (1 PVU $=10^{-6} \mathrm{~K} \mathrm{~kg}^{-1} \mathrm{~m}^{2} \mathrm{~s}^{-1}$ ); labeled above the top-right corner of each top-row panel], intraseasonal divergent wind anomalies (yellow vectors; $\mathrm{m} \mathrm{s}^{-1}$; reference vectors are located above the top-left corner of each top-row panel), and background PV (black contours; PVU; contour interval is 1 PVU, beginning at 1 PVU). Pentads correspond to those in Fig. 3. Columns are ordered as in Fig. 1. Statistically significant advection values are stippled, and vectors are plotted where their corresponding anomalies are statistically significant. The black boxes in each panel outline the averaging box referenced in section 3b(1). (d), (f) Red TC symbols mark the grid point at the center of the search radius used to identify TCs at lag zero.

flank (e.g., Fig. 18b). The anticyclone evolves equatorward in conjunction with these accelerations, which yields an anticyclonic circulation tendency to its south and a cyclonic circulation tendency to its north (tendency not shown).

Erosion of convective forcing over the Maritime Continent and Southeast Asia triggers a deceleration of the subtropical jet streak over Japan. Westerly momentum contained in this jet streak is transferred eastward primarily by the advection of the background zonal wind by the intraseasonal zonal wind (term 1b; Fig. 19) and, to a lesser extent, by the advection of the intraseasonal zonal wind by the background meridional wind (term 2a; not shown). This process yields a significant and abrupt westerly intraseasonal zonal wind acceleration (westerly wind surge) across the length of the North Pacific Ocean, which manifests as an elongated branch of the subtropical jet that spans the basin (Figs. 19c,d). Injection of westerly momentum into the jet yields a departure from geostrophic balance across the region. The Coriolis force responds by torquing the zonal wind equatorward and building northerly acceleration (Fig. 20b). This process enables a transfer of mass from the developing trough over the North Pacific (south of Alaska) to the ridge to its south. Zonal ridge expansion occurs in both directions as these accelerations concentrate on its eastern and western flanks, and it loses amplitude at its center as the meridional pressure gradient force associated with the strong geopotential gradient between it and the North Pacific trough builds poleward acceleration (Fig. 20d) and facilitates mass transfer in this direction. Downstream of this trough, momentum accumulates to the east of the North Pacific jet exit region and yields intraseasonal ridge amplification across eastern North America.

\section{Conclusions and future work}

A 200-hPa zonal momentum budget was performed to investigate the role that western North Pacific TCs 


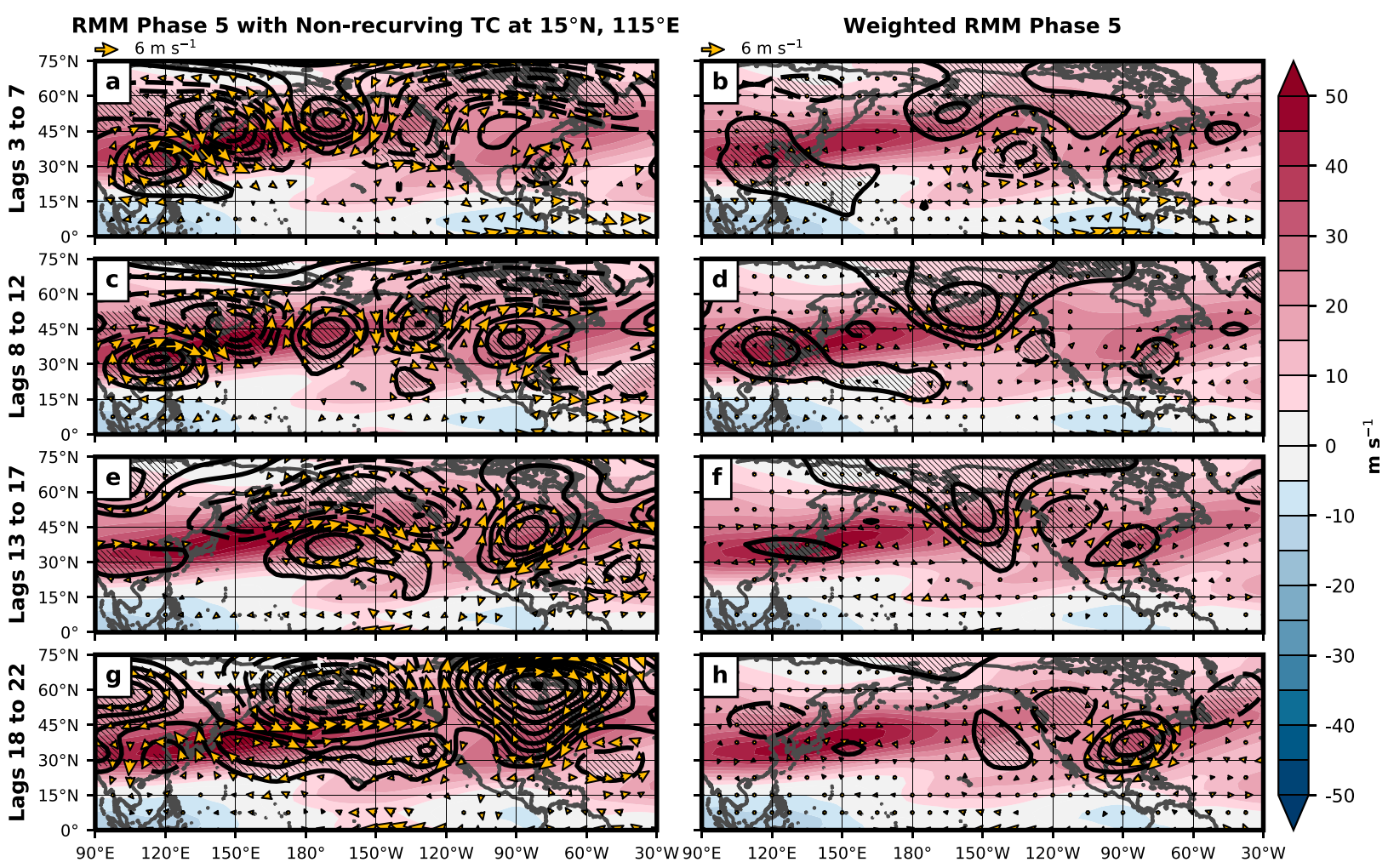

FIG. 17. Pentad-mean intraseasonal filtered 200-hPa geopotential height anomalies (black contours; gpm; solid contours indicated positive values; contour interval is $10 \mathrm{gpm}$, beginning at $\pm 10 \mathrm{gpm}$ ), vector wind anomalies (yellow vectors; $\mathrm{m} \mathrm{s}^{-1}$; a reference vector is located above the top-left corner of each top-row panel), and the $200-\mathrm{hPa}$ background zonal wind (color shading; $\mathrm{m} \mathrm{s}^{-1}$ ). Each pentad is represented by a row, and all days included in each pentad are labeled along the $y$ axis of their corresponding left-column panel. (a),(c),(e),(g) The TC-based RMM phase-5 composite and (b),(d),(f),(h) the full population RMM phase-5 composite. Statistically significant geopotential height anomalies are stippled, and vectors are plotted where their corresponding anomalies are statistically significant.

play in helping to organize and progress intraseasonal extratropical circulation anomalies that occur with MJO events that include them. Composites of relevant budget terms were generated from a subset of RMM phase-5 dates that included nonrecurving TCs within a $7.5^{\circ}$ search radius centered on $15^{\circ} \mathrm{N}, 115^{\circ} \mathrm{E}$. These composites were compared to another set generated from the full list of RMM phase-5 dates without regard for TC presence in order to assess differences in predominant momentum sources between each event set and determine the extent to which these differences can be attributed to TC presence in the TC-based composite.

Figure 21 provides a schematic depiction of the primary zonal momentum sources and scale interactions pertaining to the TC-based composite. Each panel is arranged relative to the order in which mechanisms highlighted in sections $3 b(2), 3 b(3)$, and $3 c$ are described. The intraseasonal subtropical jet (depicted by a yellow arrow in each panel of Fig. 21) intensifies in association with TC passage to its south (Fig. 21a) and is further strengthened and maintained by accelerations (denoted by blue arrows in Fig. 21b) that are tied to the growing intraseasonal upper-level subtropical ridge (marked $\mathrm{H}^{*}$ ) centered on Southeast Asia. A stronger Rossby wave response relative to that in the full population composite (not shown) emerges a few days later as the subtropical jet continues to amplify (Fig. 21c), which is consistent with past studies that have related jet strength to extratropical Rossby wave amplitude (e.g., Sardeshmukh and Hoskins 1988; Lukens et al. 2017). Finally, when intraseasonal convection begins to wane, westerly momentum built up across Southeast Asia is advected eastward by the background and intraseasonal zonal wind, yielding rapid subtropical jet extension across the length of the North Pacific Ocean (Fig. 21d). No analogous momentum surge occurs in the full population composite (not shown).

The set of TCs examined herein directly contributes to the organization of the intraseasonal extratropical circulation. Transient latent heat release and associated upper-level outflow (poleward-oriented green arrows proximate to the TC symbol in Fig. 21a) accompanying 


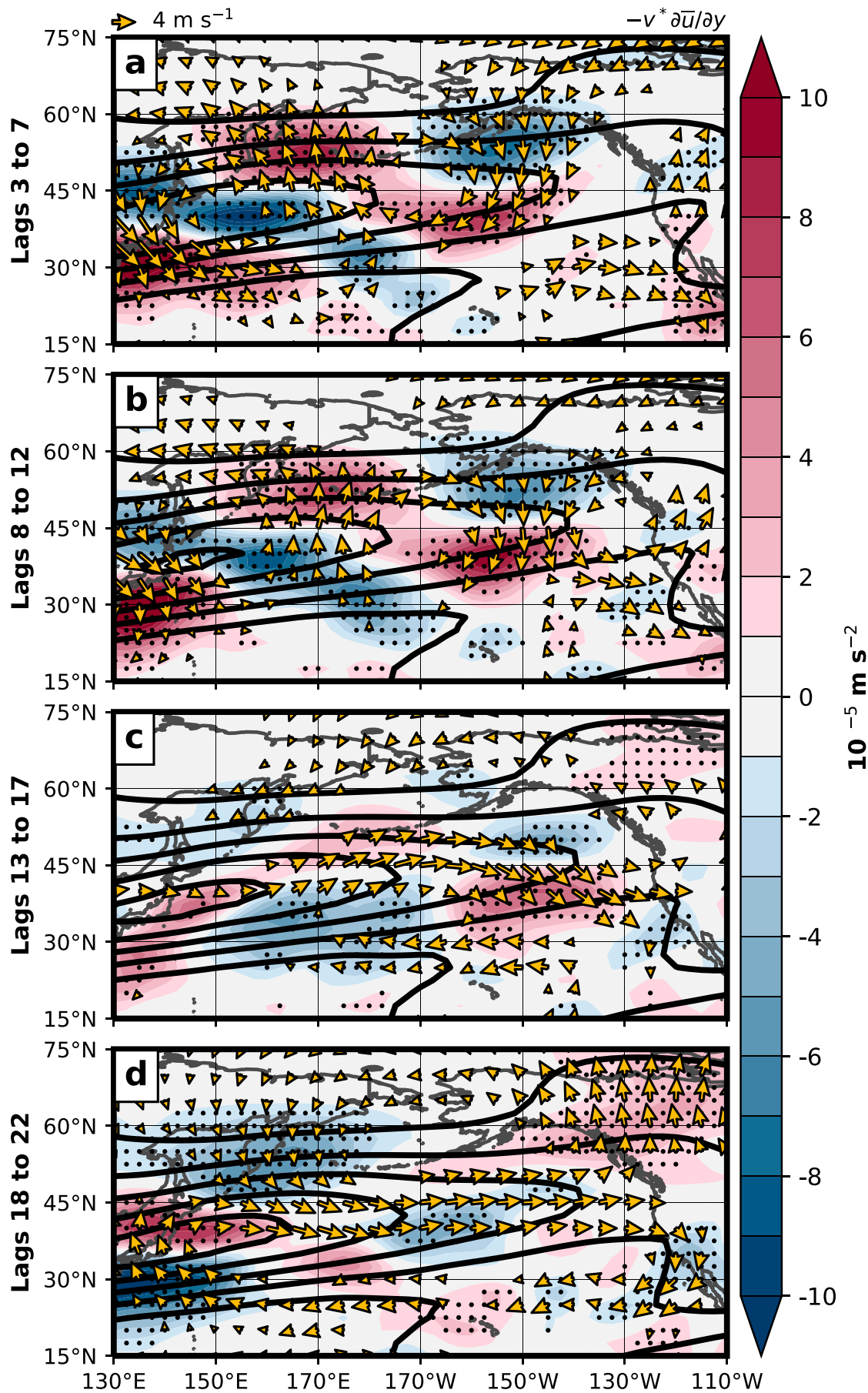

FIG. 18. Pentad-mean 200-hPa advection of background zonal wind by intraseasonal meridional wind (term $2 \mathrm{~b}$; color shading; $1 \times 10^{5} \mathrm{~m} \mathrm{~s}^{-2}$; labeled above the top-right corner of the top-row panel), intraseasonal vector wind anomalies (yellow vectors; $\mathrm{m} \mathrm{s}^{-1}$; a reference vector is located above the top-left corner of the top-row panel), and the 200-hPa background zonal wind (black contours; $\mathrm{m} \mathrm{s}^{-1}$; solid contours indicate positive values; contour interval is $10 \mathrm{~m} \mathrm{~s}^{-1}$, beginning at $\pm 10 \mathrm{~m} \mathrm{~s}^{-1}$ ). Pentads correspond to those in Fig. 17 . Statistically significant term values are stippled, and vectors are plotted where their corresponding anomalies are statistically significant. 


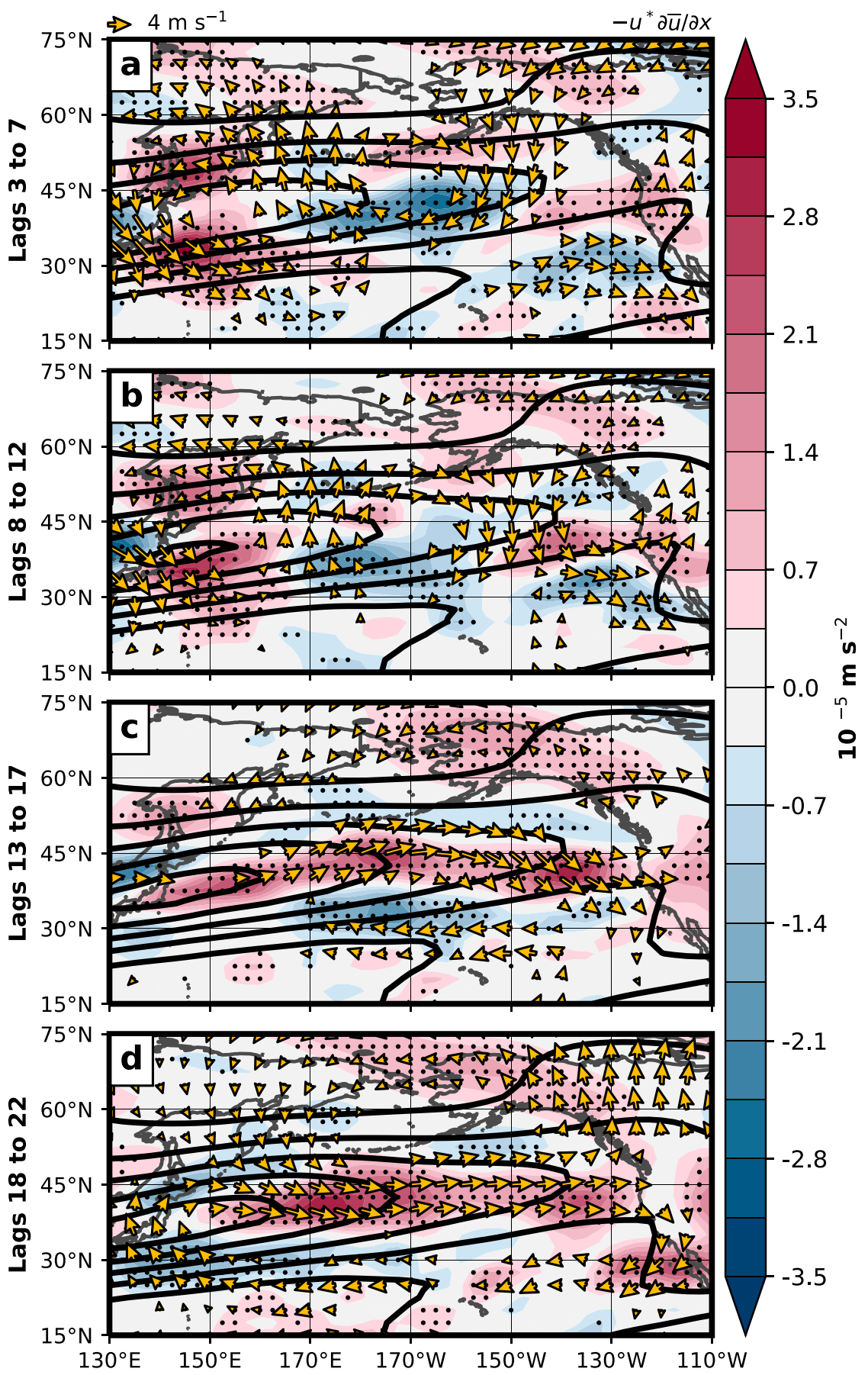

FIG. 19. As in Fig. 18, but for the 200-hPa advection of background zonal wind by intraseasonal zonal wind (term $1 \mathrm{~b}$ ).

the composite TC and/or poleward-displaced enhanced rainfall yield a strengthening and meridional elongation of a transient upper-level subtropical ridge anomaly over Southeast Asia, which constructively interferes with a preexisting transient extratropical ridge anomaly to its north. Anticyclonic flow around this anomaly draws transient westerly momentum on its poleward flank equatorward (depicted by the equatorwardoriented green arrow on the northeast side of the transient anomalous anticyclone marked $\mathrm{H}^{\prime}$ in Fig. 21a), yielding positive zonal momentum acceleration to the west of the subtropical jet exit region. Although not 

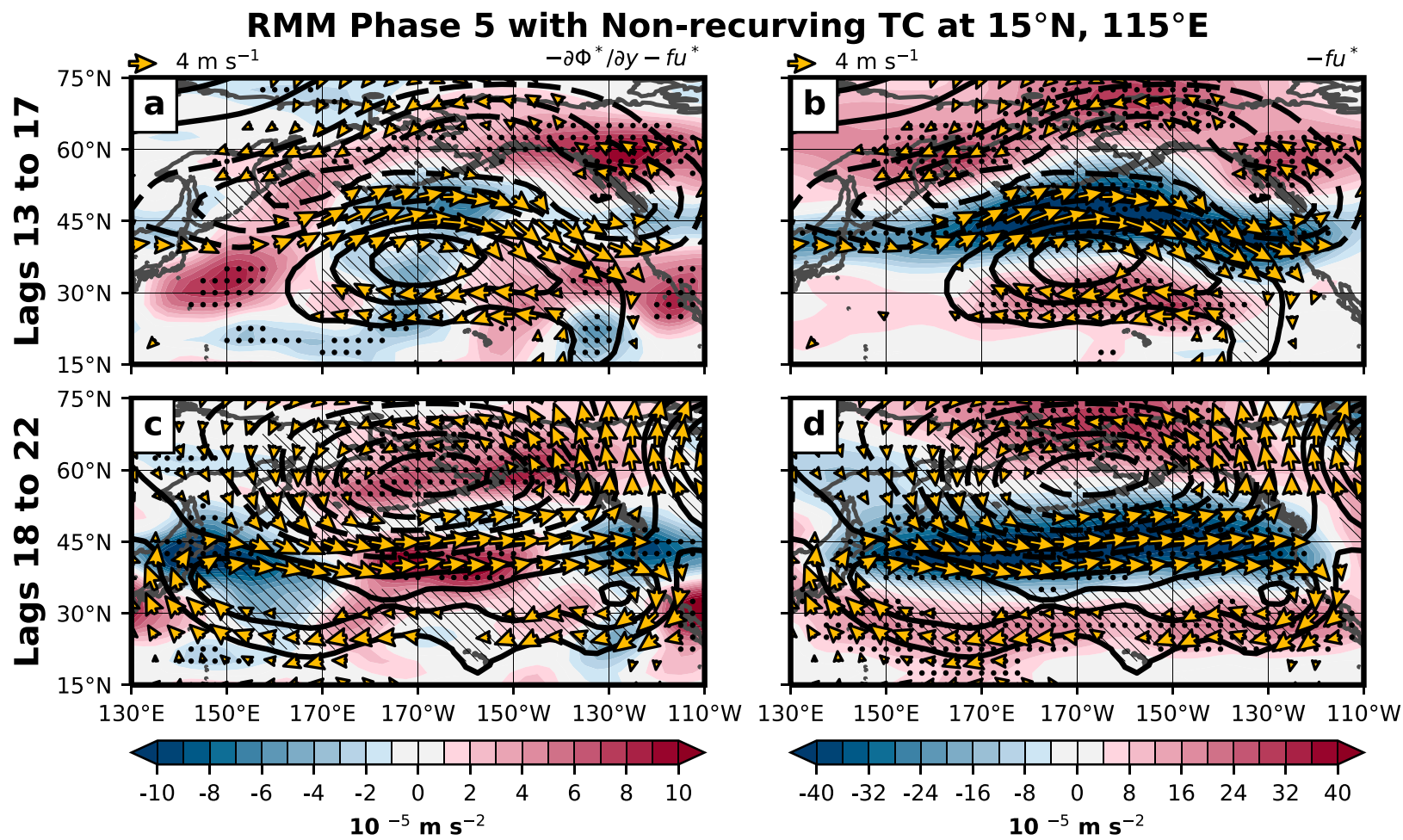

FIG. 20. (a),(c) The pentad-mean sum of the 200-hPa intraseasonal meridional pressure (geopotential) gradient force and Coriolis torque on the intraseasonal zonal wind [color shading; scale below (c); $1 \times 10^{5} \mathrm{~m} \mathrm{~s}^{-2}$; labeled above the top-right corner of (a)], intraseasonal filtered 200-hPa geopotential height anomalies (black contours; gpm; solid contours indicate positive values; contour interval is $10 \mathrm{gpm}$, beginning at $\pm 10 \mathrm{gpm}$ ), and intraseasonal vector wind anomalies [yellow vectors; $\mathrm{m} \mathrm{s}^{-1}$; a reference vector is located above the top-left corner of (a)]. (b),(d) As in (a) and (c), respectively, but for only the Coriolis torque component of the term plotted therein. Term values in (b) and (d) are shaded according to the color scale below (d). Each pentad is represented by a row, and all days included in each pentad are labeled along the $y$ axis of their corresponding left-column panel. Statistically significant term values are stippled, and vectors are plotted where their corresponding anomalies are statistically significant.

addressed in this study, anomalous transient flux convergence over Japan (denoted by the two green arrows coming together poleward of the yellow arrow in Fig. 21a) might also promote subtropical jet amplification. The transient anomalous circulation pattern reverses at later lags (not shown) and facilitates a continuation of positive zonal momentum acceleration across the same geographical area, thereby yielding a positive zonal momentum source that assists subtropical jet intensification and projects onto intraseasonal time scales.

The previous paragraph describes the manner in which TCs directly contribute to the growth of the intraseasonal subtropical jet in the TC-based composite. Results are consistent with the hypothesis that TCs can indirectly modulate intraseasonal circulations over a longer period of time to the extent that their immediate contributions are integrated into the more slowly evolving circulation and carried forward by other processes. In the TC-based composite, these processes include accelerations related to the horizontal pressure gradient force and Coriolis torque (curved blue arrows in Fig. 21b), advection of the background zonal wind by the intraseasonal zonal and meridional wind (e.g., equatorward-oriented straight blue arrows in Fig. 21b), and other smaller advection terms. One way to further test this hypothesis is to perform a set of modeling experiments wherein one experiment features initial conditions with simultaneous MJO and TC activity, while another has all TC-related circulation and moisture anomalies dampened or removed. Such a set of experiments can help to quantify the extent to which the large-scale extratropical circulation response changes in the absence of TC-related forcings. Changes in the extratropical circulation related to the presence or absence of TCs might feed back onto tropical circulation anomalies and, consequently, affect the structure and organization of subsequent MJO events (e.g., Roundy 2014; Sakaeda and Roundy 2015). Testing these hypotheses will further the understanding of TC function in the context of the global circulation. 


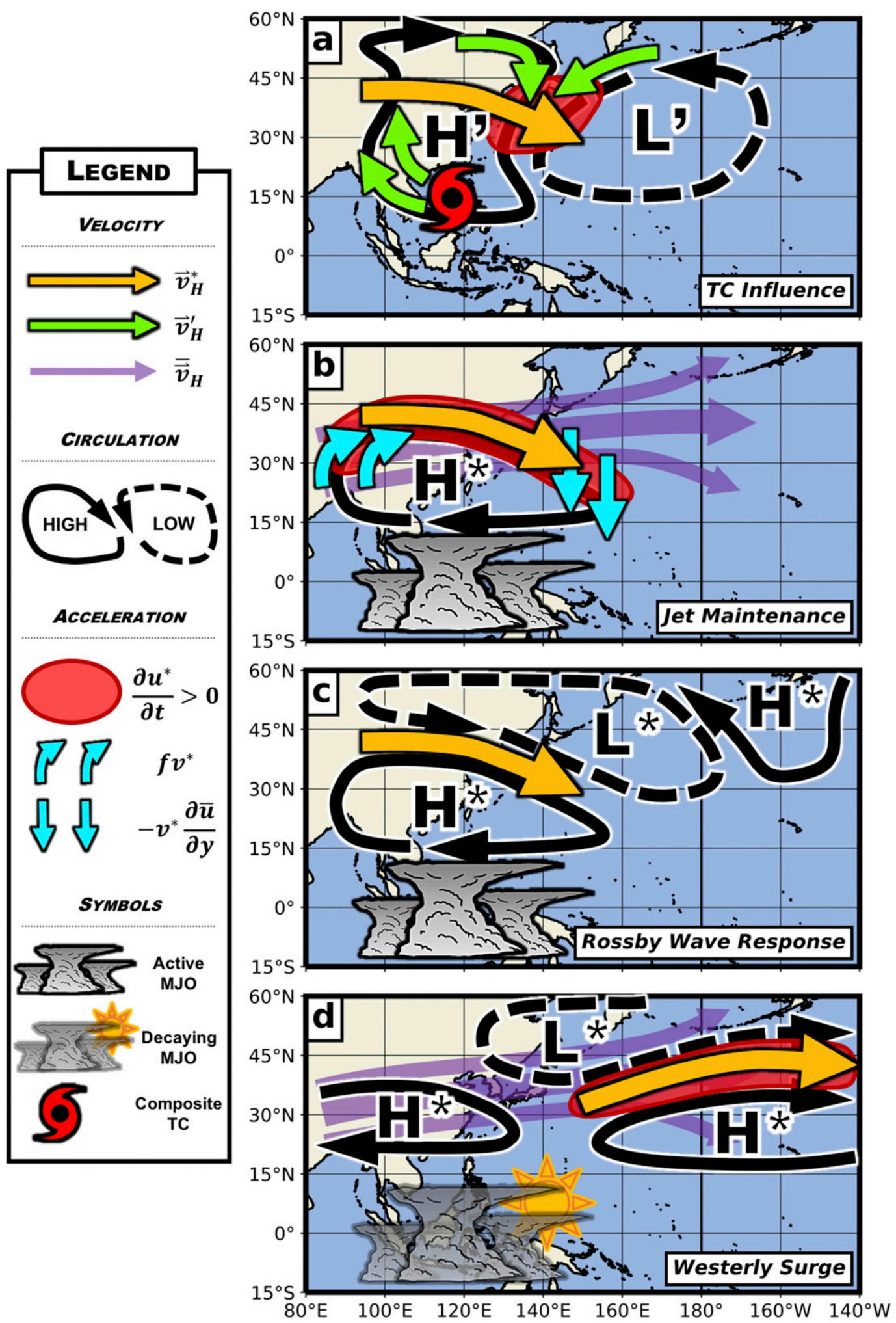


Acknowledgments. The authors wish to thank three anonymous reviewers for providing constructive commentary that has contributed to an improved manuscript. Funding was provided by National Science Foundation Grants AGS1358214, AGS1757342, and AGS1128779 to Paul Roundy. The NOAA PSD provided OLR data, and reanalysis data were provided by the NCAR CISL Research Data Archive.

\section{REFERENCES}

Aiyyer, A., and J. Molinari, 2008: MJO and tropical cyclogenesis in the Gulf of Mexico and eastern Pacific: Case study and idealized numerical modeling. J. Atmos. Sci., 65, 2691-2704, https://doi.org/10.1175/2007JAS2348.1.

Alvarez, M. S., C. S. Vera, G. N. Kiladis, and B. Liebmann, 2016: Influence of the Madden Julian oscillation on precipitation and surface air temperature in South America. Climate Dyn., 46, 245-262, https://doi.org/10.1007/s00382-015-2581-6.

Archambault, H. M., L. F. Bosart, D. Keyser, and J. M. Cordeira, 2013: A climatological analysis of the extratropical flow response to recurving western North Pacific tropical cyclones. Mon. Wea. Rev., 141, 2325-2346, https://doi.org/10.1175/ MWR-D-12-00257.1.

Barrett, B. S., and L. M. Leslie, 2009: Links between tropical cyclone activity and Madden-Julian oscillation phase in the North Atlantic and northeast Pacific basins. Mon. Wea. Rev., 137, 727-744, https://doi.org/10.1175/2008MWR2602.1.

Barton, Y., P. Giannakaki, H. von Waldow, C. Chevalier, S. Pfahl, and O. Martius, 2016: Clustering of regional-scale extreme precipitation events in southern Switzerland. Mon. Wea. Rev., 144, 347-369, https://doi.org/10.1175/MWR-D-15-0205.1.

Camargo, S. J., M. C. Wheeler, and A. H. Sobel, 2009: Diagnosis of the MJO modulation of tropical cyclogenesis using an empirical index. J. Atmos. Sci., 66, 3061-3074, https://doi.org/ 10.1175/2009JAS3101.1.

Cordeira, J. M., and L. F. Bosart, 2010: The antecedent large-scale conditions of the "perfect storms" of late October and early November 1991. Mon. Wea. Rev., 138, 2546-2569, https://doi.org/ 10.1175/2010MWR3280.1.

Donald, A., H. Meinke, B. Power, A. H. N. Maia, M. C. Wheeler, N. White, R. C. Stone, and J. Ribbe, 2006: Near-global impact of the Madden-Julian oscillation on rainfall. Geophys. Res. Lett., 33, L09704, https://doi.org/10.1029/2005GL025155.

Frank, W. M., and P. E. Roundy, 2006: The role of tropical waves in tropical cyclogenesis. Mon. Wea. Rev., 134, 2397-2417, https:// doi.org/10.1175/MWR3204.1.

Gaffney, S. J., 2004: Probabilistic curve-aligned clustering and prediction with regression mixture models. Ph.D. thesis, University of California, Irvine, 281 pp., https://www.ics.uci.edu/ sgaffney/ papers/sgaffney_thesis.pdf.

Gloeckler, L. C., and P. E. Roundy, 2019: A statistical evaluation of western North Pacific tropical cyclone contributions to largescale extratropical circulations associated with the MaddenJulian oscillation. J. Atmos. Sci., 76, 583-604, https://doi.org/ 10.1175/JAS-D-18-0228.1.

Grams, C. M., and S. R. Blumer, 2015: European high-impact weather caused by the downstream response to the extratropical transition of North Atlantic Hurricane Katia (2011). Geophys. Res. Lett., 42, 8738-8748, https://doi.org/10.1002/ 2015 GL066253.
Higgins, R. W., J.-K. E. Schemm, W. Shi, and A. Leetmaa, 2000: Extreme precipitation events in the western United States related to tropical forcing. J. Climate, 13, 793-820, https://doi.org/ 10.1175/1520-0442(2000)013<0793:EPEITW>2.0.CO;2.

Jin, F., and B. J. Hoskins, 1995: The direct response to tropical heating in a baroclinic atmosphere. J. Atmos. Sci., 52, 307-319, https://doi.org/10.1175/1520-0469(1995)052<0307:TDRTTH> 2.0.CO;2.

Jones, C., D. E. Waliser, K. M. Lau, and W. Stern, 2004: Global occurrences of extreme precipitation and the Madden-Julian oscillation: Observations and predictability. J. Climate, 17, 4575-4589, https://doi.org/10.1175/3238.1.

Keen, R. A., 1982: The role of cross-equatorial tropical cyclone pairs in the Southern Oscillation. Mon. Wea. Rev., 110, 1405-1416, https://doi.org/10.1175/1520-0493(1982)110<1405: TROCET $>2.0 . \mathrm{CO} ; 2$.

Kiladis, G. N., K. H. Straub, and P. T. Haertel, 2005: Zonal and vertical structure of the Madden-Julian oscillation. J. Atmos. Sci., 62, 2790-2809, https://doi.org/10.1175/JAS3520.1.

Klotzbach, P. J., 2010: On the Madden-Julian oscillation-Atlantic hurricane relationship. J. Climate, 23, 282-293, https://doi.org/ 10.1175/2009JCLI2978.1.

Knapp, K. R., S. Applequist, H. J. Diamond, J. P. Kossin, M. Kruk, and C. Schreck, 2010a: NCDC International Best Track Archive for Climate Stewardship (IBTrACS) Project, version 3, revision 6. NOAA National Centers for Environmental Information, accessed 30 July 2014, https://doi.org/10.7289/V5NK3BZP.

—_, M. C. Kruk, D. H. Levinson, H. J. Diamond, and C. J. Neumann, 2010b: The International Best Track Archive for Climate Stewardship (IBTrACS): Unifying tropical cyclone data. Bull. Amer. Meteor. Soc., 91, 363-376, https://doi.org/ 10.1175/2009BAMS2755.1.

L'Heureux, M. L., and R. W. Higgins, 2008: Boreal winter links between the Madden-Julian oscillation and the Arctic Oscillation. J. Climate, 21, 3040-3050, https://doi.org/10.1175/ 2007JCLI1955.1.

Liebmann, B., H. H. Hendon, and J. D. Glick, 1994: The relationship between tropical cyclones of the western Pacific and Indian Oceans and the Madden-Julian oscillation. J. Meteor. Soc. Japan, 72, 401-412, https://doi.org/10.2151/jmsj1965.72.3_401.

Lukens, K. E., S. B. Feldstein, C. Yoo, and S. Lee, 2017: The dynamics of the extratropical response to Madden-Julian oscillation convection. Quart. J. Roy. Meteor. Soc., 143, 1095-1106, https://doi.org/10.1002/qj.2993.

Madden, R. A., and P. R. Julian, 1994: Observations of the 40-50-day tropical oscillation-A review. Mon. Wea. Rev., 122, 814-837, https://doi.org/10.1175/1520-0493(1994)122<0814:OOTDTO > 2.0.CO;2.

Maloney, E. D., and D. L. Hartmann, 2000: Modulation of eastern North Pacific hurricanes by the Madden-Julian oscillation. J. Climate, 13, 1451-1460, https://doi.org/10.1175/1520-0442(2000) 013<1451:MOENPH>2.0.CO;2.

Matsueda, S., and Y. Takaya, 2015: The global influence of the Madden-Julian oscillation on extreme temperature events. J. Climate, 28, 4141-4151, https://doi.org/10.1175/JCLI-D14-00625.1.

Matthews, A. J., G. Pickup, S. C. Peatman, P. Clews, and J. Martin, 2013: The effect of the Madden-Julian oscillation on station rainfall and river level in the Fly River system, Papua New Guinea. J. Geophys. Res. Atmos., 118, 10 926-10 935, https:// doi.org/10.1002/jgrd.50865.

Moore, R. W., O. Martius, and T. Spengler, 2010: The modulation of the subtropical and extratropical atmosphere in the Pacific basin 
in response to the Madden-Julian oscillation. Mon. Wea. Rev., 138, 2761-2779, https://doi.org/10.1175/2010MWR3194.1.

Parker, T. J., G. J. Berry, and M. J. Reeder, 2013: The influence of tropical cyclones on heat waves in southeastern Australia. Geophys. Res. Lett., 40, 6264-6270, https://doi.org/10.1002/ 2013 GL058257.

Riddle, E. E., M. B. Stoner, N. C. Johnson, M. L. L'Heureux, D. C. Collins, and S. B. Feldstein, 2013: The impact of the MJO on clusters of wintertime circulation anomalies over the North American region. Climate Dyn., 40,1749-1766, https://doi.org/ 10.1007/s00382-012-1493-y.

Roundy, P. E., 2012: The spectrum of convectively coupled Kelvin waves and the Madden-Julian oscillation in regions of low-level easterly and westerly background flow. J. Atmos. Sci., 69, 21072111, https://doi.org/10.1175/JAS-D-12-060.1.

_ 2014: Some aspects of Western Hemisphere circulation and the Madden-Julian oscillation. J. Atmos. Sci., 71, 2027-2039, https://doi.org/10.1175/JAS-D-13-0210.1.

Saha, S., and Coauthors, 2010a: The NCEP Climate Forecast System Reanalysis. Bull. Amer. Meteor. Soc., 91, 1015-1057, https://doi.org/10.1175/2010BAMS3001.1.

_ - and Coauthors, 2010b: NCEP Climate Forecast System Reanalysis (CFSR) 6-hourly products, January 1979 to December 2010. Computational and Information Systems Laboratory Research Data Archive, accessed 23 March 2018, https:// doi.org/10.5065/D6DN438J.

- , and Coauthors, 2011: NCEP Climate Forecast System version 2 (CFSv2) 6-hourly products. Computational and Information Systems Laboratory Research Data Archive, accessed 23 March 2018, https://doi.org/10.5065/D61C1TXF.

_ , and Coauthors, 2014: The NCEP Climate Forecast System version 2. J. Climate, 27, 2185-2208, https://doi.org/10.1175/ JCLI-D-12-00823.1.

Sakaeda, N., and P. E. Roundy, 2015: The development of uppertropospheric wind over the Western Hemisphere in association with MJO convective initiation. J. Atmos. Sci., 72, 3138-3160, https://doi.org/10.1175/JAS-D-14-0293.1.

Sardeshmukh, P. D., and B. J. Hoskins, 1988: The generation of global rotational flow by steady idealized tropical divergence.
J. Atmos. Sci., 45, 1228-1251, https://doi.org/10.1175/15200469(1988)045<1228:TGOGRF $>2.0$. CO;2.

Schreck, C. J., III, and Coauthors, 2015: Natural gas prices and the extreme winters of 2011/2012 and 2013/2014: Causes, indicators, and interactions. Bull. Amer. Meteor. Soc., 96, 18791894, https://doi.org/10.1175/BAMS-D-13-00237.1.

Seiki, A., and Y. N. Takayabu, 2007: Westerly wind bursts and their relationship with intraseasonal variations and ENSO. Part II: Energetics over the western and central Pacific. Mon. Wea. Rev., 135, 3346-3361, https://doi.org/10.1175/MWR3503.1.

Sobel, A. H., and E. D. Maloney, 2000: Effect of ENSO and the MJO on western North Pacific tropical cyclones. Geophys. Res. Lett., 27, 1739-1742, https://doi.org/10.1029/1999GL011043.

Wheeler, M. C., and H. H. Hendon, 2004: An all-season real-time multivariate MJO index: Development of an index for monitoring and prediction. Mon. Wea. Rev., 132, 1917-1932, https:// doi.org/10.1175/1520-0493(2004)132<1917:AARMMI> 2.0.CO;2.

Wilks, D. S., 2006: On "field significance" and the false discovery rate. J. Appl. Meteor. Climatol., 45, 1181-1189, https://doi.org/ 10.1175/JAM2404.1.

_ 2016: "The stippling shows statistically significant grid points": How research results are routinely overstated and overinterpreted, and what to do about it. Bull. Amer. Meteor. Soc., 97, 2263-2273, https://doi.org/10.1175/BAMS-D-15-00267.1.

$\mathrm{Yu}, \mathrm{Y}$., and M. M. Rienecker, 1998: Evidence of an extratropical atmospheric influence during the onset of the 1997-1998 El Niño. Geophys. Res. Lett., 25, 3537-3540, https://doi.org/ 10.1029/98GL02628.

Zhang, C., 2005: Madden-Julian oscillation. Rev. Geophys., 43, RG2003, https://doi.org/10.1029/2004RG000158.

Zhou, S., M. L'Heureux, S. Weaver, and A. Kumar, 2012: A composite study of the MJO influence on the surface air temperature and precipitation over the continental United States. Climate Dyn., 38, 1459-1471, https://doi.org/10.1007/s00382-011-1001-9.

Zhu, C.-W., T. Nakazawa, and J.-P. Li, 2003: Modulation of twin tropical cyclogenesis by the MJO westerly wind burst during the onset period of 1997/98 ENSO. Adv. Atmos. Sci., 20, 882898, https://doi.org/10.1007/BF02915512. 